\title{
Evaluation of seismic assessment procedures for determining deformation demands in $\mathrm{RC}$ wall buildings
}

\author{
Matthew J. Fox ${ }^{* 1}$, Timothy J. Sullivan ${ }^{2,3}$ and Katrin Beyer ${ }^{4}$ \\ ${ }^{1}$ Rose Programme, UME School, IUSS Pavia, Italy \\ ${ }^{2}$ Department of Civil Engineering and Architecture, University of Pavia, Italy \\ ${ }^{3}$ EUCENTRE, Pavia, Italy \\ ${ }^{4}$ School of Architecture, Civil and Environmental Engineering, \\ École Polytechnique Fédéral de Lausanne, Switzerland
}

(Received January 4, 2015, Revised April 12, 2015, Accepted April 22, 2015)

\begin{abstract}
This work evaluates the performance of a number of seismic assessment procedures when applied to a case study reinforced concrete (RC) wall building. The performance of each procedure is evaluated through its ability to accurately predict deformation demands, specifically, roof displacement, inter-storey drift ratio and wall curvatures are considered as the key engineering demand parameters. The different procedures include Direct Displacement-Based Assessment, nonlinear static analysis and nonlinear dynamic analysis. For the latter two approaches both lumped and distributed plasticity modelling are examined. To thoroughly test the different approaches the case study building is considered in different configurations to include the effects of unequal length walls and plan asymmetry. Recommendations are made as to which methods are suited to different scenarios, in particular focusing on the balance that needs to be made between accurate prediction of engineering demand parameters and the time and expertise required to undertake the different procedures. All methods are shown to have certain merits, but at the same time a number of the procedures are shown to have areas requiring further development. This work also highlights a number of key aspects related to the seismic response of $\mathrm{RC}$ wall buildings that may significantly impact the results of an assessment. These include the influence of higher-mode effects and variations in spectral shape with ductility demands.
\end{abstract}

Keywords: seismic assessment; reinforced concrete (RC); direct displacement-based assessment

\section{Introduction}

To evaluate the seismic risk posed by existing structures it is necessary for engineers to have access to accurate and reliable methods of seismic assessment. This work provides a comparative review of the performance of a number of different assessment procedures applied to modern reinforced concrete $(\mathrm{RC})$ wall buildings. The primary objective is to identify the benefits and drawbacks of the different procedures. In particular a focus is placed on the trade-off between accuracy and reliability for simplicity and expediency. The work also highlights particular aspects

*Corresponding author, Ph.D. Candidate, E-mail: matthew.fox@umeschool.it 
of the behaviour of RC wall buildings that may not be adequately accounted for by different assessment procedures. It is envisaged that the results of this study will assist practitioners in identifying which assessment procedure is most suited to their needs for a particular application.

The different assessment procedures considered are Direct Displacement-Based Assessment ${ }^{1}$ (DDBA), nonlinear static analysis (NSA) and nonlinear dynamic analysis (NDA). The selected assessment procedures are compared through their application to an eight storey case study building, designed in accordance with Eurocode 8 Part 1 (EC8-1) (CEN, 2004). The case study building has four rectangular walls in the direction being considered and is configured in several different ways to test the procedures against various complexities, including unequal wall lengths and plan asymmetry. The assessments are conducted at multiple intensity levels to capture the performance of the methods across a range of expected levels of seismic response. Throughout the work, different modelling procedures are evaluated, including lumped-plasticity and distributedplasticity approaches. Nonlinear dynamic analysis with a lumped plasticity model is used as a benchmark to compare the other approaches against. This approach was taken as a benchmark as it is considered to be the traditional modelling strategy for nonlinear dynamic analyses. Assessments are limited to only the consideration of deformations, specifically: roof displacement, inter-storey drift ratio (herein shortened to simply 'drift' or IDR) and curvature demands. Evaluation of shear forces and bending moments is not considered as part of this work.

This article is organised into eight different sections. Following the introduction the next section (Section 2) describes the case study building and defines the objective of the seismic assessment. The following section (Section 3) provides the details of the different assessment procedures and different numerical modelling techniques used in this work. The three sections after this give the results of the assessments for the three different configurations of the case study building along with discussion (Sections 4,5 and 6). The last part of the paper provides recommendations on the choice of appropriate assessment methods for $\mathrm{RC}$ wall buildings and conclusions.

\section{The case study building and assessment objective}

The case study building used throughout this work is the eight storey RC wall building shown in Fig. 1. The building has been kept intentionally very simple to aid in identifying differences in the results of the assessment procedures. In plan the building measures $24 \mathrm{~m}$ in the NS-direction and $30 \mathrm{~m}$ in the EW-direction. The distributed seismic mass at each floor level is $0.82 \mathrm{t} / \mathrm{m}^{2}$ (or 8 $\mathrm{kPa}$ ), which gives a total seismic mass at each level of $587 \mathrm{t}$ and a rotational mass moment of inertia about the vertical axis of $7.22 \times 10^{4} \mathrm{tm}^{2}$. In the EW-direction lateral loads are resisted by four RC walls (W1-W4) and in the NS-direction by two RC walls (W5 and W6). All walls are rectangular with a thickness of $0.25 \mathrm{~m}$. Gravity loads are predominantly carried by slender columns that are assumed to provide no contribution to the lateral strength or stiffness of the building.

Seismic excitation is considered in the EW-direction only. The choice of an eight storey building allows for some examination of higher-mode effects, however, future work may consider

\footnotetext{
${ }^{1}$ Direct Displacement-Based Assessment refers to the approach described in Priestley et al. (2007) and is one approach from a broad class of displacement-based design and assessment procedures
} 


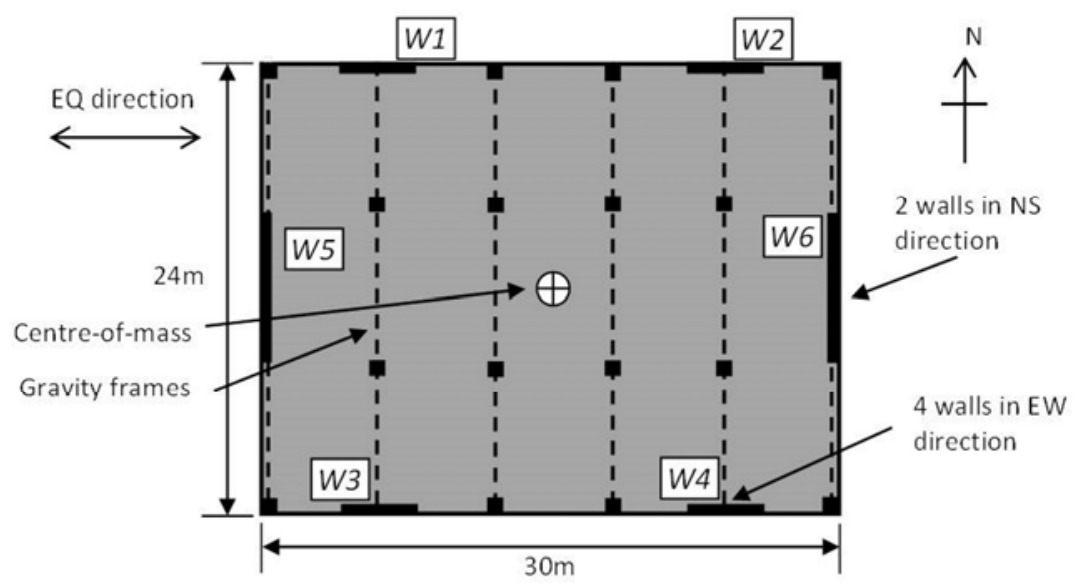

Fig. 1 Plan view of case study building

taller buildings where higher modes will have a more significant influence on response.

Three different configurations of the case study building, each with an increasing level of complexity, are considered. In the first configuration, walls $W 1-W 4$ are all $5 \mathrm{~m}$ long. The assessment of this building thus reduces to that of a single cantilever wall. In the second configuration walls $W 1$ and $W 3$ are $6 \mathrm{~m}$ long and walls $W 2$ and $W 4$ are $3 \mathrm{~m}$ long. In this configuration the assessment reduces to that of a system of two cantilever walls rigidly connected at each floor level i.e., the floor diaphragms are assumed to be rigid in plane. In the third configuration walls $W 1$ and $W 2$ are $6.5 \mathrm{~m}$ long and walls $W 3$ and $W 4$ are $3.5 \mathrm{~m}$ long. This results in a building that is asymmetric in plan and therefore the walls in the NS-direction influence the response of the building in the EW-direction. Walls $W 5$ and $W 6$ are chosen to be $6.5 \mathrm{~m}$ long so that they provide a reasonable level of torsional restraint. From herein the three different configurations are referred to as Simple Cantilever, Unequal Length Walls and Torsional, respectively.

The detailed design of each configuration (i.e., reinforcing contents and checks for code compliance) was carried out in accordance with EC8-1 (CEN 2004) using modal response spectrum analysis. The design seismicity was represented by the EC 8 type 1 spectrum for ground type $\mathrm{C}$ with a design ground acceleration on type A ground of $a_{g}=0.2 \mathrm{~g}$. This represents a moderate level of seismicity. The designs were carried out following the requirements for a ductility class 'medium' (DCM) building and the key design outputs are provided in Table 1. The parameters $\rho_{v}$ and $\rho_{h}$ are respectively the vertical and horizontal reinforcing ratios at ground level, $T_{1}$ is the fundamental period of the building, and $e_{r}$ and $e_{v}$ are respectively the stiffness and strength eccentricities in the NS-direction expressed as fractions of the buildings plan dimension in the $\mathrm{EW}$-direction, $b$. The characteristic values for reinforcing yield strength and concrete strength are $500 \mathrm{MPa}$ and $30 \mathrm{MPa}$ respectively.

The objectives of a seismic assessment may vary significantly depending on the needs of the client. For example, in a modern reliability focused seismic assessment it may be necessary to estimate the expected annual economic losses due to earthquakes or perhaps the annual probability of collapse. At the other end of the scale an assessment may be largely qualitative e.g., assessing the potential for soft-storey collapse in frame buildings. In this work the objective of the assessment is to determine the expected response of the building subject to a given level of 
Table 1 Key outputs from wall design in accordance with EC8-1

\begin{tabular}{|c|c|c|c|c|c|c|c|c|c|c|c|}
\hline \multirow{2}{*}{ Configuration } & \multicolumn{4}{|c|}{$\rho_{v}(\%)$} & \multicolumn{4}{|c|}{$\rho_{h}(\%)$} & \multirow{2}{*}{$\begin{array}{l}T_{1}^{*} \\
\text { (s) }\end{array}$} & \multirow{2}{*}{$e_{r} / b^{*}$} & \multirow{2}{*}{$e_{v} / b^{*}$} \\
\hline & W1 & W2 & W3 & W4 & W1 & W2 & W3 & W4 & & & \\
\hline Simple cantilever & 0.73 & 0.73 & 0.73 & 0.73 & 0.21 & 0.21 & 0.21 & 0.21 & $\begin{array}{c}2.47 \\
(1.74)\end{array}$ & 0 & 0 \\
\hline $\begin{array}{l}\text { Unequal length } \\
\text { walls }\end{array}$ & 0.72 & 0.96 & 0.72 & 0.96 & 0.21 & 0.25 & 0.21 & 0.25 & $\begin{array}{l}2.76 \\
(1.74)\end{array}$ & 0 & 0 \\
\hline Torsional & 0.59 & 0.59 & 0.68 & 0.68 & 0.16 & 0.16 & 0.18 & 0.18 & $\begin{array}{c}2.62 \\
(1.75)\end{array}$ & $\begin{array}{l}-0.25 \\
(-0.29)\end{array}$ & -0.17 \\
\hline
\end{tabular}

*Bracketed values calculated using $50 \%$ gross section properties. Non-bracketed values calculated using secant stiffness to yield

**Longitudinal reinforcing content in the transverse walls ( W5 \& W6) was $0.91 \%$ and governed by design for seismic actions in the NS direction

seismicity. Four different intensities are assessed with the EC8 type 1 spectrum for ground type C at $a_{g}=0.1 \mathrm{~g}, a_{g}=0.2 \mathrm{~g}, a_{g}=0.3 \mathrm{~g}$ and $a_{g}=0.4 \mathrm{~g}$. The first three intensity levels are intended to approximately correspond to the minimum damage causing event, the design level event, and the maximum credible earthquake, respectively. The $a_{g}=0.4 \mathrm{~g}$ intensity has been included to ensure a thorough comparison of the methods and corresponds to a scenario where seismicity is reevaluated at a site and increased. For the aforementioned spectrum, two different spectraldisplacement corner periods (between the constant velocity and constant displacement regions of the spectrum) are considered: $T_{D}=2 \mathrm{~s}$ and $T_{D}=4 \mathrm{~s}$. This is done to assess the effects of spectral shape on response, including the relative contribution of higher-mode effects and the influence of having $T_{1}$ near $T_{D}$.

As mentioned previously, the expected response is measured through the following engineering demand parameters (EDPs): maximum roof displacement, maximum inter-storey drift ratio and maximum wall curvature. The latter two EDPs can both be easily related to structural damage and drift can also be used to estimate expected damage in non-structural elements. On the other hand roof displacement cannot be easily related to damage; however, it is a useful parameter for comparing the different assessment procedures. Here the performance levels used in the displacement-based design model code DBD12 (Sullivan et al. 2012), which defines the three performance levels in Table 2 along with corresponding drift and material strain limits, will be adopted. These limits are based on earlier recommendations made by Priestley et al. (2007) and it should be noted that the 'No Damage' limit state refers to no damage requiring repair e.g., no epoxy injection of cracks. The material strain limits are converted to curvature limits (separately for each building configuration), which are easier to work with. Material strain limits should be provided for both concrete and reinforcing; however, in this case the walls have high levels of confining reinforcing and so the (longitudinal) reinforcing material strain limits govern over the concrete strain limits.

A number of significant assumptions are employed across all assessment procedures:

- Expected material strengths are used $\left(f^{\prime}{ }_{c e}=1.3 f^{\prime}{ }_{c}\right.$ and $\left.f_{y e}=1.1 f_{y}\right)$ rather than characteristic strengths.

- Strength reduction factors are not used in the assessments.

- For lumped plasticity models the flexural stiffness (EI) of members is based on the secant stiffness to yield, as recommended by Priestley et al. (2007). 
Table 2 Performance levels as defined in DBD12 (Sullivan et al. 2012)

\begin{tabular}{ccc}
\hline $\begin{array}{c}\text { Performance } \\
\text { level }\end{array}$ & $\begin{array}{c}\text { IDR limit } \\
(\%)\end{array}$ & $\begin{array}{c}\text { Reinforcing } \\
\text { strain limit }\end{array}$ \\
\hline No Damage (ND) & $0.7^{*}$ & 0.015 \\
Repairable Damage (RD) & 2.5 & 0.05 \\
No Collapse (NC) & No limit $^{* *}$ & 0.08 \\
\hline
\end{tabular}

*For a building with ductile non-structural elements

**Although no exact limit is provided, an IDR limit at the No Collapse performance level can be related to P- $\Delta$ stability checks

- Shear stiffness is taken as the gross shear stiffness reduced by the ratio of effective to gross flexural stiffness, where the effective flexural stiffness is based on secant stiffness to yield. This approach is recommended by Priestley et al. (2007) for shear stiffness prior to yield and shear cracking and is not intended for structures responding in the inelastic range. However, given that all walls in the case study building are rather slender, shear deformations are not expected to be significant and so a simple approach to shear stiffness is justified.

- Accidental mass eccentricity is not considered.

Further assumptions specific to the different assessment procedures are stated in the relevant sub-sections.

\section{Assessment procedures}

As stated previously, three general categories of assessment are used in this work: Direct Displacement-Based Assessment (DDBA), nonlinear static analysis (NSA), and nonlinear dynamic analysis (NDA). The three different categories of assessment vary significantly in terms of their levels of sophistication and the time and resources that their use demands. Two different approaches to the NSA assessment are considered: the NSA procedure in accordance with EC8 (Part 1, CEN 2004, Part 3, CEN 2005) and the modal pushover analysis procedure of Chopra and Goel $(2002,2004)$. Brief descriptions of each method are provided in the following sub-sections. For the assessment procedures requiring nonlinear numerical models, both lumped plasticity and distributed plasticity modelling approaches were considered. The background on these different modelling strategies and their relative merits and limitations are discussed towards the end of the section.

\section{Direct Displacement-Based Assessment}

The DDBA procedure used in this work is taken from Priestley et al. (2007), but updated to match the more recent DBD12 model code (Sullivan et al. 2012). Generally speaking, DDBA can be considered the reverse procedure to Direct Displacement-Based Design (DDBD) (Priestley et al. 2007). In DDBD the engineer must determine the system strength required to achieve a desired performance level subject to a known level of seismicity. DDBA on the other hand starts with known system strength and it is then necessary to determine the level of seismicity that causes a particular performance level to be reached. DDBA is explained in more detail with reference to Fig. 2. 
The first stage in the procedure (Fig. 2a) is to convert the multi-degree-of-freedom (MDOF) stucture into an equivalent single-degree-of-freedom (SDOF) representation. The SDOF representation is characterised by an effective mass, $m_{e}$, and an effective height, $H_{e}$, given by Eqs. (1) and (2) respectively

$$
\begin{aligned}
& m_{e}=\frac{\left[\sum_{i=1}^{n}\left(m_{i} \Delta_{i}\right)\right]^{2}}{\sum_{i=1}^{n}\left(m_{i} \Delta_{i}^{2}\right)} \\
& H_{e}=\frac{\sum_{i=1}^{n}\left(m_{i} \Delta_{i} h_{i}\right)}{\sum_{i=1}^{n}\left(m_{i} \Delta_{i}\right)}
\end{aligned}
$$

where $m_{i}$ is the seismic mass at storey $i, h_{i}$ is the height of story $i$ and $\Delta_{i}$ is the lateral displacement at storey $i$. The displacements at each story are determined from available equations for different structural systems that relate the displaced shape of the structure to EDPs of interest, such as drift and curvature.

In the second stage (Fig. 2b), the properties pertaining to the nonlinear force-displacement response are determined. This primarily refers to the base shear, $V_{\text {Base }}$, yield displacement, $\Delta_{y}$, and characteristic displacement, $\Delta_{d}$, which is determined for the point at which the structure is at the limit of the performance level being assessed. From these values the effective stiffness, $K_{e}$, and displacement ductility, $\mu$, can be determined

$$
\begin{array}{r}
\Delta_{y}=\frac{\sum_{i=1}^{n}\left(m_{i} \Delta_{y i}{ }^{2}\right)}{\sum_{i=1}^{n}\left(m_{i} \Delta_{y i}\right)} \\
\Delta_{d}=\frac{\sum_{i=1}^{n}\left(m_{i} \Delta_{i}^{2}\right)}{\sum_{i=1}^{n}\left(m_{i} \Delta_{i}\right)} \\
K_{e}=\frac{F_{u}}{\Delta_{d}} \\
\mu=\frac{\Delta_{d}}{\Delta_{y}}
\end{array}
$$

In stage three (Fig. 2c), the displacement ductility is used to determine an equivalent viscous damping (EVD) ratio. The EVD ratio is used to account for the hysteretic energy dissipated by the 


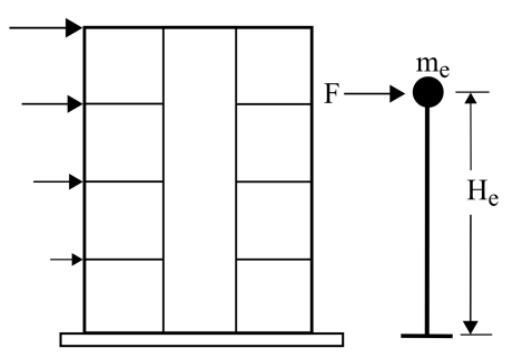

(a) SDOF Simulation

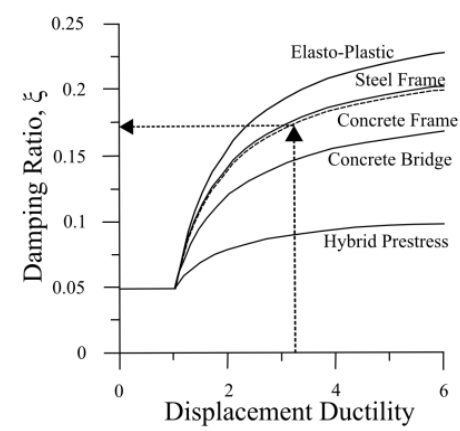

(c) Equivalent damping vs. ductility

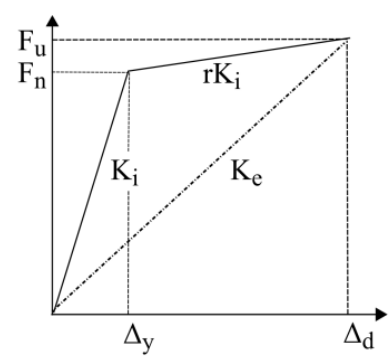

(b) Effective Stiffness $K_{e}$

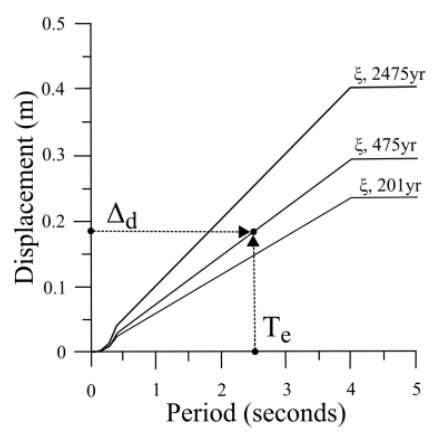

(D) Displacement Spectra

Fig. 2 Fundamentals of Direct Displacement-Based Assessment (adapted from Priestley et al. 2007).

structure and allows the SDOF representation to be treated as a linear system with an effective (secant) stiffness and increased viscous damping. In the final stage shown (Fig. 2d), the effective stiffness and effective mass are used to determine the effective period of the SDOF system. The characteristic displacement and effective period then form a unique co-ordinate through which an elastic displacement spectrum passes. This displacement spectrum corresponds to the EVD ratio found in stage 3 and a return period, which is the desired output of the assessment. Welch et al. (2014) and Sullivan et al. (2014) have also been exploring ways of extending the method to make allowances for uncertainties in demand and capacity, quickly consider multiple hazard levels and estimate expected annual losses. However, the focus of this study is to compare intensity-based assessment methods. Also note that once the allowable intensity has been identified (as per Fig. $2 \mathrm{~d}$ ) it is then necessary to check any strength governed failure modes (i.e., shear failure and flexural failure above the plastic hinge region) and revise downward the acceptable intensity if these failure modes govern. However, as discussed previously. these aspects are not considered in the current paper.

One will recall from Section 2 that in this work we are given a known level of seismicity and the objective is to determine the corresponding structural response. This means the procedure just described must be applied iteratively i.e., assuming an initial value of $\Delta_{d}$, determining the corresponding level of seismicity, and then updating the initial guess of $\Delta_{d}$. This necessity to iterate is undesirable; however, it would not normally be required as it is the view of the authors that in general the more useful form of assessment is to go from performance level to seismicity. Sullivan et al. (2014) also recently explained that the DDBA approach can be applied without 
iteration for specific hazard levels through construction of inelastic acceleration-displacement response spectra but in this work, use of the traditional DDBA formulation of Fig. 2 is sufficient.

DDBA for buildings with a torsional component to response is an area of ongoing research. For this work the approach used by Priestley et al. (2007) for design is used in reverse for assessment. The approach was developed based on studies of plan asymmetric wall buildings conducted by Castillo (2004) and Beyer et al. (2008) and recognises the importance of strength eccentricity on inelastic torsional response, as discussed in Paulay (2001).

\section{Nonlinear static analysis - EC8}

The NSA procedure of EC8-1 (CEN 2004) is the basic version of the N2 method developed by Fajfar $(1999,2000)$. In assessment through NSA, or pushover analysis, a nonlinear numerical model of the structure is 'pushed over' by an increasing vector of forces or displacements. Typically this load vector has an invariant height-wise distribution (Chopra and Goel 2002) and some commonly used patterns include uniform, inverse triangular and modal distributions. There are also pushover procedures that use a non-invariant load vector, which is based on the instantaneous modal properties of the building (Gupta and Kunnath 2000, Antoniou and Pinho 2004). These 'adaptive-pushover' procedures offer some clear advantages; however, they are not considered in this work as the algorithm is only implemented in few analysis programs. EC8 requires two analyses to be run with two different force vectors; a 'modal' pattern, with forces proportional to the modal forces in the fundamental mode of vibration, and a 'uniform' pattern, with forces proportional to the mass at each level. In this work, only the 'modal' pattern is considered.

From the pushover analysis a pushover curve is obtained in terms of roof displacement versus base shear. This curve is then converted to that of an equivalent SDOF system using Eqs. (7)-(10)

$$
\begin{gathered}
F^{*}=\frac{F_{b}}{\Gamma} \\
d^{*}=\frac{d_{n}}{\Gamma} \\
m^{*}=\sum m_{i} \Phi_{i} \\
\Gamma=\frac{m^{*}}{\sum m_{i} \Phi_{i}^{2}}
\end{gathered}
$$

where $F_{b}$ is base shear, $d_{n}$ is roof displacement, $m_{i}$ is the mass at level $i$, and $\Phi_{i}$ is the normalised displacement at level $i$ (normalised such that $\Phi_{n}=1$ ). In this case, because the load shape and displacements are proportional to the mode shape, $\Gamma$ is the modal participation factor. Note that the MDOF to SDOF conversion is very similar to that used in DDBA, the difference being that the DDBA conversion is based on the inelastic displaced shape rather than the first mode vector of the elastic system.

The next step is to fit an elasto-perfectly-plastic (EPP) force-deformation relationship to the SDOF pushover curve. The procedure in EC8 requires the user to equate the deformation energy of the pushover curve and the EPP approximation up to the point at which a plastic mechanism 
forms. For RC walls modelled using distributed plasticity fibre-section elements it is difficult to identify the point at which a mechanism forms. Furthermore, this approach does not appear to be intended for use on pushover curves with significant softening or hardening. Given these difficulties, instead of adopting the EC8 bilinearisation scheme, this work uses the approach of FEMA-273 (FEMA 1997). FEMA-273 uses an iterative graphical approach to fit a bilinear approximation to the pushover curve. The bilinear approximation connects the following three coordinates $(0,0),\left(d_{y}{ }^{*}, F_{y}{ }^{*}\right)$ and $\left(d_{m}{ }^{*}, F_{m}{ }^{*}\right)$ as shown in Fig. 3(a). The value of $F_{y}{ }^{*}$ is first estimated and then $d_{y}{ }^{*}$ is calculated by passing the first branch of the bilinear approximation through the pushover curve at the point corresponding to $0.6 F_{y}{ }^{*}$. The deformation energy up to $d_{m}{ }^{*}$ is then calculated for both the pushover curve and the bilinear approximation. If the two energies are equal, the bilinear approximation is correct, if not, then the process is repeated with an improved estimate of $F_{y}{ }^{*}$. In the case that softening occurs, an EPP approximation is used, rather than bilinear with post-yield hardening, as recommended by Chopra and Goel (2001). It should be noted that in this case it is no longer possible to match the pushover and approximate curves at $d_{m}{ }^{*}$. An example is shown in Fig. 3(b). A discussion on the effect of different bilinearisation schemes is beyond the scope of this work and the reader is instead referred to De Luca et al. (2011).

At low intensities it is unlikely that the structure will yield and therefore only a linear approximation is required. For lumped plasticity models this is straightforward as the initial branch of the pushover curve is linear. However, for distributed plasticity the initial part of the pushover curve is nonlinear due to crack opening, as can be seen in Fig. 3. In this case a linear approximation was passed through the point on the pushover curve corresponding to $0.6 F^{*}{ }_{\text {max }}$.

The next step is to determine the displacement of the equivalent SDOF system. First the period of the structure is obtained from Eq. (11) and the corresponding elastic spectral displacement is obtained. The inelastic displacement of the SDOF system is then calculated from the elastic spectral displacement using $R-\mu-T$ relationships. The structures in this work all respond in the medium period range and therefore the equal displacement rule is used. At this point the SDOF displacement should be checked against the initial estimate of $d_{m}{ }^{*}$ and iterations carried out if necessary. Once the SDOF displacement has been obtained, the user then refers back to the corresponding step in the pushover analysis, from which the values of desired EDPs can be obtained.

$$
T^{*}=2 \pi \sqrt{\frac{m^{*} d_{y}^{*}}{F_{y}^{*}}}
$$

EC8-3 (CEN 2005) states that for NSA, higher-mode effects do not need to be considered if the criteria of EC8-1 (CEN 2004) clause 4.3.3.2.1(2)a are met, that is, if the fundamental period is less than $4 T_{C}$ and $2 \mathrm{~s}$. It is therefore debatable whether or not higher-mode effects need to be considered depending on which period estimates are used (refer Table 1). To illustrate the potential errors in some response parameters generated by neglecting higher modes, examples are provided in the following sections without higher-mode modification. However, to illustrate the full potential of the N2 method, further examples are provided with inclusion of higher-mode effects where appropriate. Higher-mode drift amplification is accounted for through the approach of Kreslin and Fajfar (2012), which scales up response using two correction factors based on the results of a standard elastic modal analysis (Chopra 2007). First, the modal analysis results are normalised such that they have the same roof displacement at the centre of mass as obtained in the standard pushover analysis, which is assumed to be unaffected by higher-modes. The first correction factor, 
for higher-mode effects in elevation, is then calculated as the ratio of normalised modal analysis drift to the nonlinear pushover drift, both at the centre of mass. The second correction factor, for higher-mode effects in plan, is taken as the ratio of the normalised modal analysis roof displacement at the location of interest to the pushover analysis roof displacement at the same location. Correction factors are then applied to response parameters of interest obtained from the pushover analysis. Note that neither correction should be used to reduce the response i.e., they have a minimum value of one.

\section{$\underline{\text { Nonlinear static analysis - MPA }}$}

The Modal Pushover Analysis procedure of Chopra and Goel $(2002,2004)$ is similar to the EC8 approach discussed previously; however, it considers not just the fundamental mode of response but also higher modes. The procedure starts with consideration of the fundamental mode as was done in the EC8 procedure described previously. It might appear to readers of both EC8 (CEN 2004), Chopra and Goel $(2002,2004)$ that the two approaches (for the fundamental mode response) are quite different. However, from a numerical point of view they are identical if the load vector is proportional to the mode shape and a common bilinearisation scheme is used. An exception to this is for plan asymmetric buildings. In this case the NSA-MPA procedure includes the torques about the vertical axis in the load vector whereas it is assumed that for the EC8 procedure the load vector only includes horizontal forces.

In the NSA-MPA procedure the pushover analyses are then repeated for all modes that contribute significantly to the total response. For the case of a medium-rise RC wall building, three modes in total should be sufficient. The contributions of the separate modes are then combined using the SRSS modal combination rule. The SRSS combination rule has a sound theoretical basis using random vibration theory for structures responding in the elastic range (see Clough and Penzien 1993). For structures responding in the inelastic range this theoretical basis no longer holds true. However, a number of researchers have shown that reasonable estimates can still be obtained by using SRSS for predicting various EDPs during inelastic response (Chopra and Goel 2002, Pennucci et al. 2014).

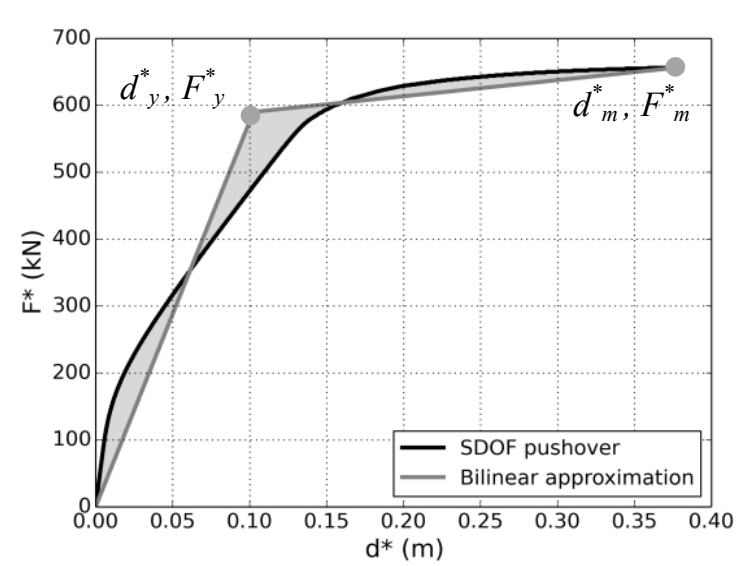

(a)

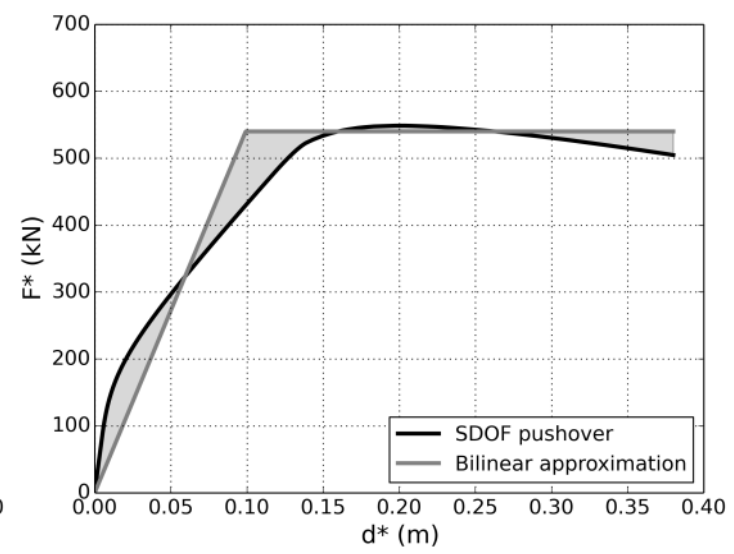

(b)

Fig. 3 Bilinearisation of pushover curves for a sample RC wall building. (a) Hardening case, and (b) softening case 


\section{Nonlinear dynamic analysis}

Assessment through nonlinear dynamic analysis is generally considered the most accurate form of assessment. In a NDA the coupled equations of motion for the multi-degree-of-freedom building are solved through numerical integration to obtain the response over (and if necessary beyond) the duration of an earthquake (see Clough and Penzien 1993). Moving from a NSA procedure to NDA there are a number of key additional considerations that must be made regarding the hysteretic response, record selection, and damping modelling. Choices regarding hysteretic behaviour are discussed later in reference to different modelling approaches whereas record selection and damping are discussed in the following paragraphs.

Record selection is a topic of significant research interest and a detailed discussion is beyond the scope of this work. Ideally a set of accelerograms should be selected that best represent the hazard at the site of interest and a number of authors have put forward recommendations on how to best address this issue (e.g., Beyer and Bommer 2007, Baker 2011). In the case at hand the records must represent the seismic hazard that is defined by the code spectrum. This presents a rather different situation and as pointed out by Iervolino et al. (2008) a number of recommendations for state-of-the-art record selection cannot be adhered to. For this work the record selection is carried out in accordance with the requirements of EC8-1 (CEN 2004). Two sets of seven accelerograms are selected, one for a corner period of $T_{D}=2 \mathrm{~s}$ and the other for $T_{D}=4 \mathrm{~s}$. In accordance with EC8-1 (CEN, 2004) the use of seven or more accelerograms allows the analyst to take the average response of the seven, rather than the maximum (for between three and six accelerograms). The records are selected and scaled so that in the period range between $0.2 T_{1}$ and $2 T_{1}$ no value of the mean $5 \%$ damped elastic spectrum is below $90 \%$ of the corresponding value of the design spectrum. In this case $T_{1}$ is taken as the fundamental period of the structure calculated using $50 \%$ of the gross section properties and thus the spectrum is matched over the range from $0.4 \mathrm{~s}$ to $4 \mathrm{~s}$. The acceleration and displacement spectra are shown in Figs. 4 and 5 for the two sets of accelerograms scaled to $a_{g}=0.2 \mathrm{~g}$. The details of the accelerograms, all of which have been selected from the SIMBAD data base (Smerzini et al. 2013), are provided in Tables 3 and 4 (scale factors are for $a_{g}=0.2 \mathrm{~g}$ ).
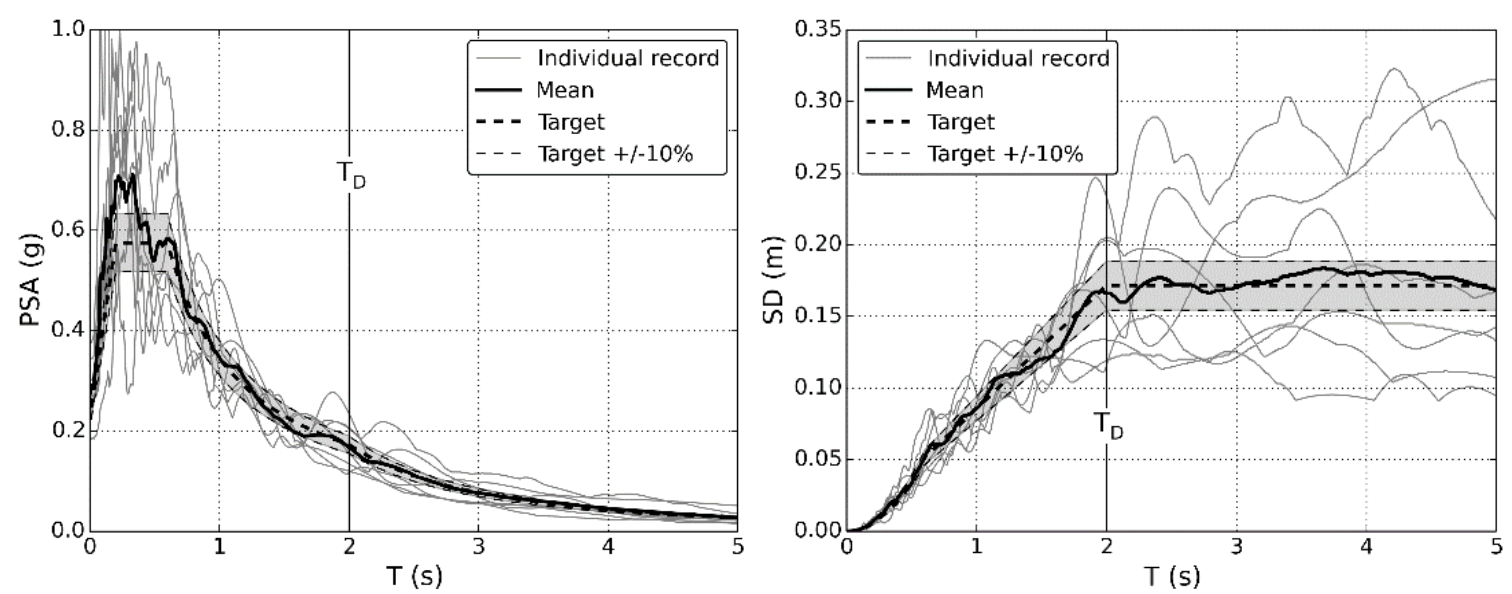

Fig. 4 5\% damped acceleration (left) and displacement (right) response spectra for $T_{D}=2 \mathrm{~s}$ record set 
Table 3 Accelerograms used in $T_{D}=2 \mathrm{~s}$ record set (Smerzini et al. 2013)

\begin{tabular}{ccccccc}
\hline \hline Earthquake Name & Station name & $\mathbf{M}_{\mathbf{W}}$ & $\begin{array}{c}\text { Epicentral } \\
\text { distance (km) }\end{array}$ & $\mathbf{V}_{\mathbf{s 3 0}}(\mathbf{m} / \mathbf{s})$ & $\begin{array}{c}\text { Scale } \\
\text { factor }\end{array}$ & Comp. \\
\hline Near Miyakejima Island & Niijima & 5.9 & 17.53 & 235 & 2.25 & EW \\
Duzce 2 & Cankiri cerkes & 6.0 & 15.23 & 348 & 3.96 & EW \\
Eastern Fukushima Pref & Iwaki & 6.6 & 26.24 & 367 & 1.96 & EW \\
Mid Nagata Pref & Shiozawa & 6.2 & 23.05 & 203 & 2.50 & NS \\
Northridge & Century City-LACC & 6.7 & 20.19 & 278 & 1.05 & $\mathrm{H} 1-90^{\circ}$ \\
Imperial Valley & El Centro Array \#4 & 6.5 & 27.03 & 208.9 & 0.71 & $\mathrm{H} 2-140^{\circ}$ \\
Northridge & Newhall-County Fire & 6.7 & 20.25 & 269 & 0.31 & $\mathrm{H} 2-360^{\circ}$ \\
\hline
\end{tabular}
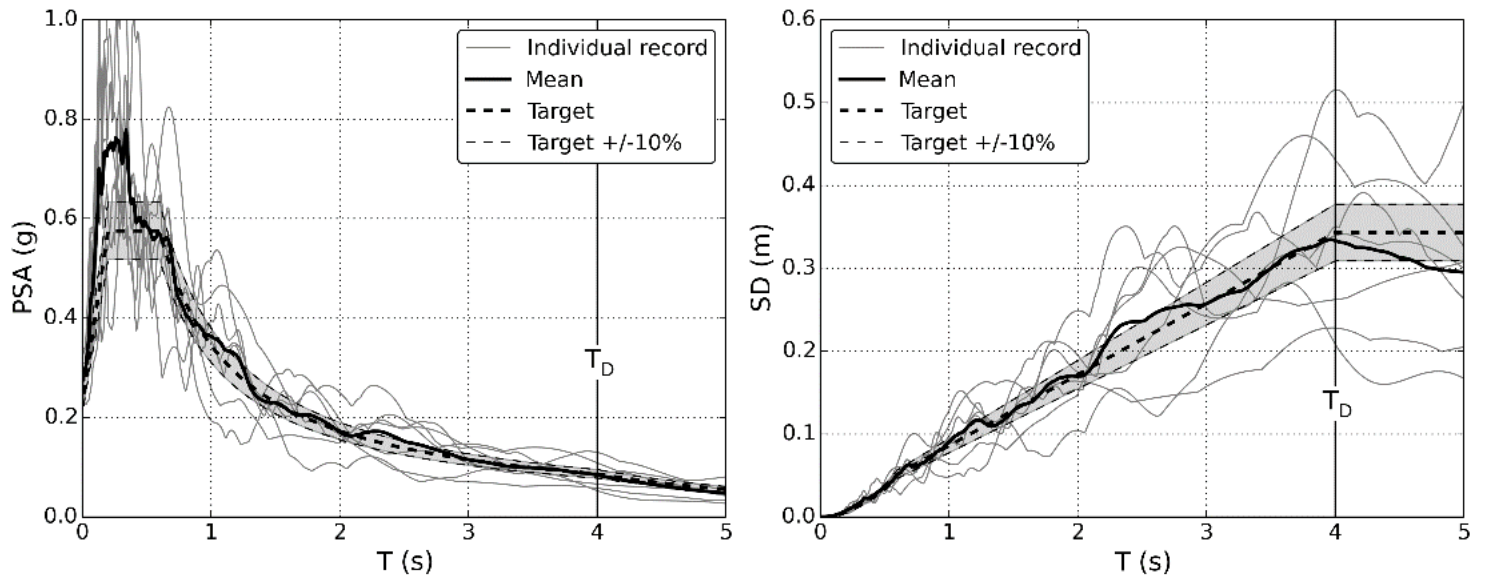

Fig. 5 5\% damped acceleration (left) and displacement (right) response spectra for $T_{D}=4 \mathrm{~s}$ record set

Table 4 Accelerograms used in $T_{D}=4 \mathrm{~s}$ record set (Smerzini et al. 2013)

\begin{tabular}{|c|c|c|c|c|c|c|}
\hline Earthquake name & Station name & $\mathbf{M}_{\mathbf{W}}$ & $\begin{array}{c}\text { Epicentral } \\
\text { distance (km) }\end{array}$ & $\mathrm{V}_{\mathrm{s} 30}(\mathrm{~m} / \mathrm{s})$ & $\begin{array}{c}\text { Scale } \\
\text { factor }\end{array}$ & Comp. \\
\hline NW Off Kyushu & Fukuoka & 6.6 & 25.96 & 195 & 1.17 & EW \\
\hline Duzce 2 & Cankiri cerkes & 6.0 & 15.23 & 348 & 4.80 & EW \\
\hline Superstition Hills & Westmorland Fire Sta & 6.6 & 19.5 & 194 & 1.61 & $\mathrm{H} 1-90^{\circ}$ \\
\hline Northridge & $\begin{array}{c}\text { Century City - LACC } \\
\text { North }\end{array}$ & 6.7 & 20.19 & 278 & 1.32 & $\mathrm{H} 1-90^{\circ}$ \\
\hline Eastern Fukushima Pref & Iwaki & 6.6 & 26.24 & 367 & 1.50 & NS \\
\hline Imperial Valley & El Centro Array \#5 & 6.5 & 27.68 & 205.6 & 0.63 & $\mathrm{H} 2-140^{\circ}$ \\
\hline Northridge & $\begin{array}{l}\text { Newhall-County Fire } \\
\text { Sta. }\end{array}$ & 6.7 & 20.25 & 269 & 0.38 & $\mathrm{H} 2-360^{\circ}$ \\
\hline
\end{tabular}

The choice of both damping ratio and damping model can have a significant effect on the outcomes of dynamic analyses (Priestley and Grant 2005, Chopra 2007, Carr 2007). The former is an issue related to all assessment procedures and there is some doubt as to what is the best choice 
of viscous damping ratio for a given structural system. In this work, $5 \%$ is used, which is a common value assumed for RC structures. In some respects the choice of damping model is more significant than the damping ratio. As a starting point Rayleigh damping is typically used as it can give quasi-constant damping ratios across a number of modes. $5 \%$ damping is specified at the first and second (or sometimes third) modes of vibration. The choice then has to be made as to whether the stiffness matrix used in the Rayleigh damping formulation should be the initial or the tangent stiffness matrix. For reasons argued by Priestley and Grant (2005) the tangent stiffness matrix is used in this work. A further recommendation from Priestley et al. (2007) is that the damping ratio at the fundamental mode should be reduced as per Eq. (12). The reason for this reduction is that at the fundamental mode Rayleigh damping is dominated by the mass proportional component. This means that as the structure moves further into the inelastic range damping may be overestimated

$$
\xi^{*}=\frac{\xi(1-0.1(\mu-1)(1-r))}{\sqrt{\mu /(1+r \mu-r)}}
$$

It is rather impractical to set damping in accordance with Eq. (12) as ductility is not known $a$ priori. For simplicity the analyses in this work have been conducted with $5 \%$ damping at the first mode for $a_{g}=0.05-0.2 \mathrm{~g}$ and a reduced value of $3 \%$ assigned for $a_{g} \geq 0.3 \mathrm{~g}$ recognizing that nonlinear response is expected at higher intensity levels and so lower values of damping should be adopted. These rough approximations were based on ductility values obtained from initial trials, which upon post analysis evaluation were found to be reasonable.

\section{Numerical modelling}

Both the NSA and NDA procedures require the use of a nonlinear numerical model. Two different broad categories of modelling strategy are considered in this work: 'lumped plasticity plastic hinge models' and 'distributed plasticity beam element models with fibre-sections', herein referred to as just 'lumped plasticity (LP)' and 'distributed plasticity (DP)'. Note that there are also models combining fibre-sections with a finite plastic hinge length, such as that proposed by Scott and Fenves (2006), however, this formulation is not considered in this work.

Lumped plasticity models use elastic frame elements with 'hinges' at the element ends in which plastic deformations are concentrated. The hinge regions need to be calibrated to a specific hysteresis rule in terms of moment-rotation. For this work the 'Takeda thin' hysteresis rule (Takeda hysteresis with parameters $\alpha=0.5$ and $\beta=0.0$. Refer Carr 2008) is employed for NDAs and NSAs (but for NSAs only the bi-linear backbone is required). The main advantage of lumped plasticity models is that they are computationally very efficient. This can be a significant advantage when conducting NDAs with a multi-storey $3 \mathrm{D}$ model and in the case when a large number of accelerograms, possibly at different intensities, are to be used. The conceptual simplicity of lumped plasticity models can also be an advantage when it comes to interpreting results.

Distributed plasticity models have come to the fore in recent years. Instead of restricting yielding to predetermined regions it is instead possible to have yielding along the full length of each element. Inelasticity is evaluated at a number of integration points along the length of the member. At each integration point the member cross-section is discretised into a number of fibres used to model the nonlinear cyclic uniaxial stress-strain relationship of the constitutive materials (reinforcing steel, unconfined concrete, and confined concrete). In this work the reinforcing steel is 
modelled using the stress-strain relationship proposed by Menegotto and Pinto (1973) coupled with the isotropic hardening rules proposed by Filippou et al. (1983). The concrete is modelled using the Mander et al. (1988) stress-strain relationship and the cyclic rules proposed by MartinezRueda and Elnashai (1997). Distributed plasticity models offer a number of advantages over lumped plasticity models:

- Inelasticity is defined at a material level and so calibration of plastic hinge moment-rotation relationship is not required.

- Moment-axial force interaction is implicitly captured by the model, although for uncoupled walls this is unlikely to be a significant factor.

- Elongation of elements due to shifting of the neutral axis is captured. Again this is unlikely to be important for uncoupled walls, but for coupled walls it may be important, as explained in Fox et al. (2014).

There are also some important drawbacks with distributed plasticity models:

- They are computationally expensive compared to equivalent lumped plasticity models.

- When a stiffness proportional damping model is used (even as a component of Rayleigh damping) erroneous axial forces will be generated in the elements (as explained by Correia et al. 2013), which in turn affect the moment-axial force relationship. To minimise these effects in this work the damping ratio specified at the second mode of vibration has been reduced to $2 \%$.

- Their apparent simplicity can be misleading. It is very simple for an inexperienced analyst to develop a distributed plasticity model and overlook some of the critical numerical issues such as element discretisation and numerical formulation. These can have a significant effect on how the results should be interpreted.

When distributed plasticity elements are used, it is necessary to consider the mathematical formulation of the elements. In this work a displacement-based formulation is used, as opposed to a force-based formulation. Force-based formulations take the forces at each integration point (fibre-section) and compute the corresponding section deformations. Numerical integration with different integration weights at different sections is then used to give the overall member deformations. Following this formulation, equilibrium must be exactly satisfied. The major drawback of force-based formulations is that they tend to overestimate curvatures at the base of a wall due to being formulated on the plane-sections-remain-plane hypothesis (Almeida et al. 2014). Displacement-based elements assume a deformation profile along the length of the member and then compute the corresponding forces at each integration section. In doing so equilibrium is only satisfied in an average sense and multiple elements may be required to accurately model a structural member (this is often irrelevant for multi-storey walls which require, as a minimum, the same number of elements as storeys). When the mesh discretisation is not fine enough it is possible to overestimate the member strength and stiffness (Almeida et al. 2014). The advantage of the displacement-based formulation is that it is possible to obtain a more realistic estimate of member curvatures if an appropriate element discretisation is chosen (despite being still bound to the plane-sections-remain-plane requirement). The formulation of these beam elements is based on the assumption of a linear curvature profile along the length of the element, i.e., the same profile which is also assumed over the height of a plastic hinge. To obtain similar strain predictions with such beam element models as one would obtain from plastic hinge models (which have been calibrated against experimental data), the element length at the base should be set (by the user) equal to the plastic hinge length, as is done in this work. Above the first floor level, one element is used per storey. For a more detailed discussion on this modelling choice, readers are referred to Yazgan and Dazio (2010). The plastic hinge length can be calculated using Eq. (13) from DBD12 
(Sullivan et al. 2012), which has been developed from an earlier equation by Priestley et al. (2007)

$$
L_{P}=k H_{n}+0.2 L_{w}+L_{S P}
$$

where $k=0.15\left(f_{u} / f_{y}-1\right), f_{u}$ and $f_{y}$ are respectively the ultimate and yield reinforcing stresses, $H_{n}$ is the total height of the wall, $L_{w}$ is the length of the wall and $L_{S P}=0.022 f_{y} d_{b l}(\mathrm{~N}, \mathrm{~mm})$ is the strain penetration length, where $d_{b l}$ is the reinforcing bar diameter. Two different software packages are used for the numerical modelling. Seismostruct v6.5 (Seismosoft 2013) is used for all distributed plasticity models. It is also used for the NSAs with lumped plasticity models in the cases where there is significant post yield softening due to P- $\Delta$ effects. Ruaumoko (Carr 2012) is used for all other analyses due to its inclusion of Giberson one component frame elements (for lumped plasticity modelling) and its comparative simplicity in modelling rigid floor diaphragms in 3D structures.

\section{Results for the simple cantilever wall building}

This section presents the assessment results for the simple cantilever wall building. The results presented focus on either interesting features of the response of $\mathrm{RC}$ wall buildings or interesting comparisons between the assessment procedures.

Fig. 6(a) shows the maximum displacement at roof level, $\Delta_{n}$, for each method at each intensity level for the $T_{D}=2 \mathrm{~s}$ spectrum. Fig. 6(b) shows the same results but as a ratio of the value found from method- $i$ to the value found from the NDA assessment with a lumped plasticity model (NDA-LP), which is used as the benchmark approach. This format of presenting results will be used throughout the remainder of the article. As mentioned previously, roof displacement cannot be easily related to damage and as such is not commonly used as an EDP. It does however allow for a good initial comparison of the methods because it is relatively insensitive to higher-mode effects. At low intensities (i.e., before yielding) there is virtually no difference between the methods despite significant variations in stiffness between different modelling strategies (i.e., DP models allow some sections to remain uncracked). At higher intensities, once yielding starts to occur, the results begin to diverge. DDBA is non-conservative while the NSA procedures are conservative compared to the benchmark approach. This is due to the different assumptions used to relate inelastic displacement to elastic spectral demand. The NSA procedures use the 'equal displacement rule' (Veletsos and Newmark 1960) whereas DDBA uses the substitute structure concept with equivalent viscous damping (Gulkan and Sozen 1974, Priestley et al. 2007). It is particularly important to note here that the equations for equivalent viscous damping in DDBA are more suited to situations in which the effective period of the structure is less than the corner period $T_{D}$. In this case not only the effective period but also the initial period, are longer than $T_{D}$, thus the non-conservative result.

Figs. 7(a) and 7(b) show the assessed roof displacement response of the case study building located at a site characterised by a displacement spectrum with $T_{D}=4 \mathrm{~s}$. The initial first mode period of the structure is now less than $T_{D}$ and it can be seen that the discrepancy between NSA and DDBA results tends to reduce. However, as the initial first mode period is now in the constant velocity range of the spectrum (i.e., $S d(T) \propto T$ ) the variations in stiffness have a significant effect on response. It can be seen that the DP models tend to have a reduced response compared to their LP counterparts. For dynamic analyses this difference occurs only at low intensities where the 


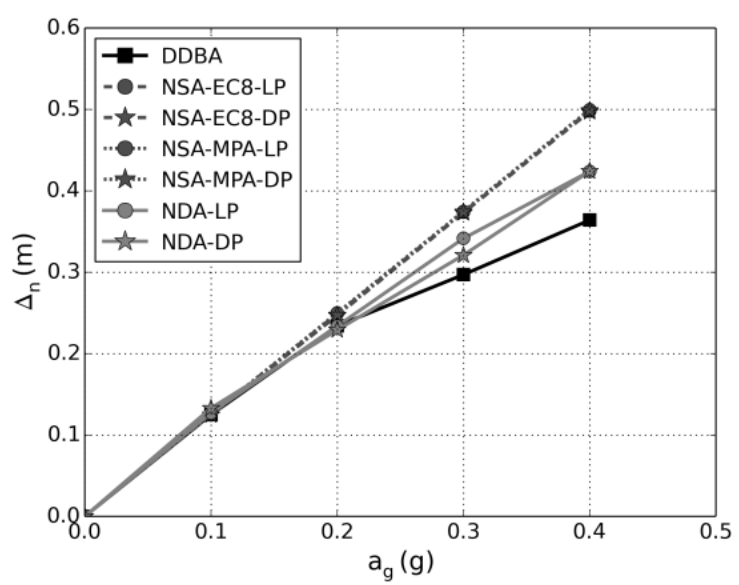

(a)

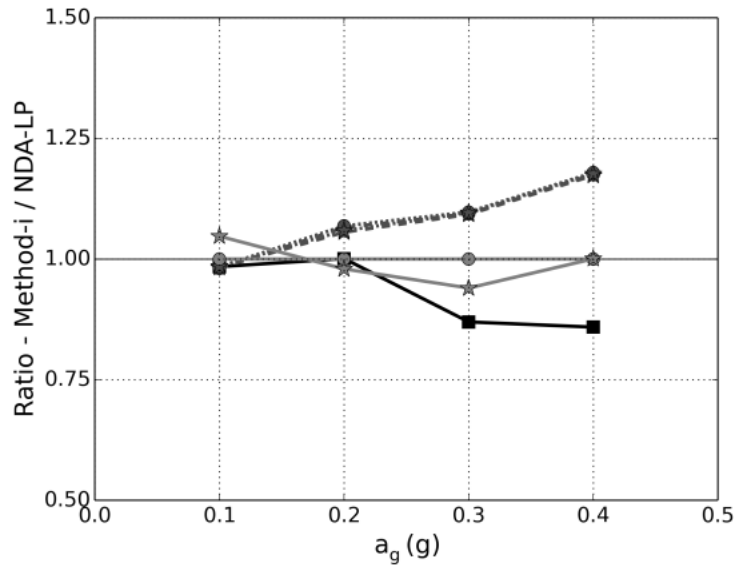

(b)

Fig. 6 Peak roof displacements versus seismic intensity for $T_{D}=2 \mathrm{~s}$ spectrum. (a) Absolute values, and (b) ratios to the NDA-LP benchmark method

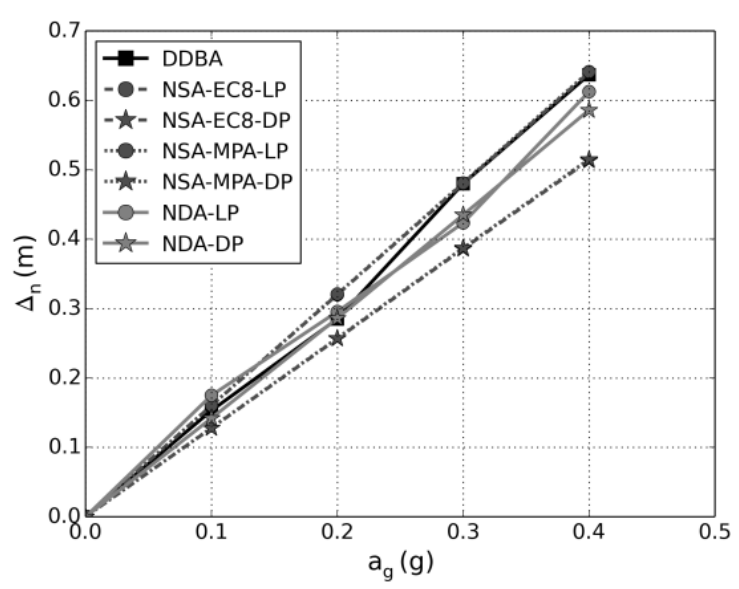

(a)

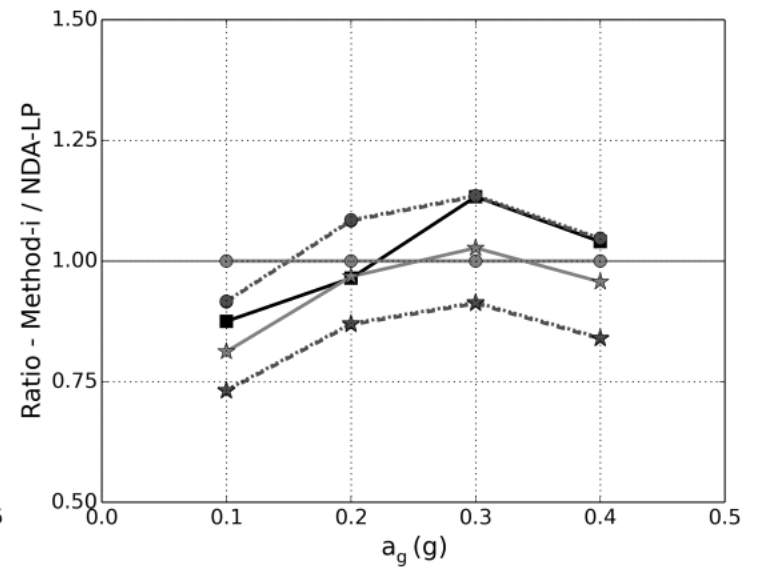

(b)

Fig. 7 Peak roof displacements versus seismic intensity for $T_{D}=4 \mathrm{~s}$ spectrum. (a) Absolute values, and (b) ratios to the NDA-LP benchmark method

displacement response is strongly related to the initial stiffness. For the NSA procedures the difference is relatively constant across all intensities and is due to the bi-linear approximation of the DP pushover being stiffer than the equivalent LP model.

Inter-storey drift ratio is an important EDP as it can be related to both structural and nonstructural damage. Fig. 8 shows the drift response for the $T_{D}=2 \mathrm{~s}$ spectrum. It can be seen that even though stiffness has little effect on displacement (Fig. 6) it can significantly affect the calculated inter-storey drift ratios. This is observed in Fig. 8(b) where the results obtained from DP models tend to be less than their LP counterparts (which had lower initial stiffness owing to cracking assumptions), particularly at low intensities. Fig. 8(a) shows the limits of the performance levels described in Section 2. In this case the No Damage limit is reached at around $a_{g}=0.1 \mathrm{~g}$ and the Repairable Damage limit is approached at around $0.4 \mathrm{~g}$. This indicates that drift related damage is unlikely to be significant for this structure. 


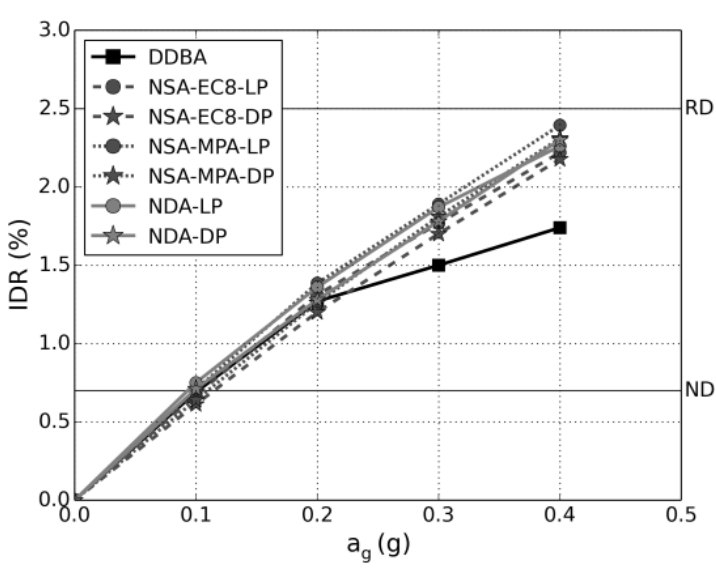

(a)

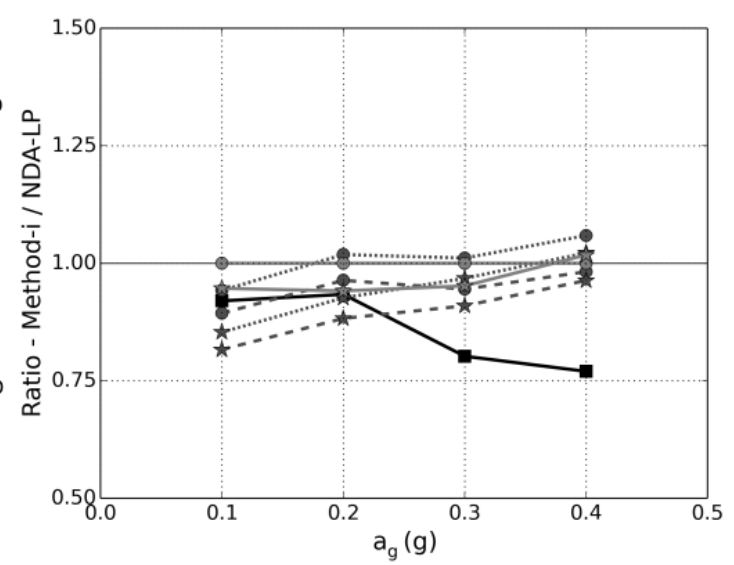

(b)

Fig. 8 Peak inter-storey drift ratio versus seismic intensity for $T_{D}=2 \mathrm{~s}$ spectrum. (a) Absolute values, and (b) ratios to the NDA-LP benchmark method

Drift demand is generally expected to be influenced by higher modes; however, given that the building is only eight storeys, higher-mode effects were not expected to be too significant. To investigate the influence of higher-mode effects on drift, Fig. 9(a) shows an ad hoc higher-mode drift amplification factor. This drift amplification factor is taken as the ratio of normalised drifts found from nonlinear dynamic to those obtained from nonlinear static analysis. The drifts are normalised in each case by the roof displacement (i.e., $\operatorname{IDR}_{\text {norm }}=\mathrm{IDR} / \Delta_{\mathrm{n}}$ ), which is assumed to be relatively unaffected by higher modes. The higher-mode amplification factors are determined for both the EC8 and MPA procedure (using the lumped plasticity models) and for both the $T_{D}=2 \mathrm{~s}$ and $T_{D}=4 \mathrm{~s}$ spectra. The obtained factors range up to 1.2 showing that higher-mode effects are indeed significant. Furthermore, it can be observed that the amplification is generally larger for the $T_{D}=2 \mathrm{~s}$ spectrum. This is because the higher-mode displacement demands relative to the fundamental mode are larger for the $T_{D}=2 \mathrm{~s}$ spectrum as shown in Fig. 9(b). Fig. 9(a) also shows that despite the MPA procedure considering multiple modes of vibration it still underestimates drift relative to NDA. This can be attributed to the fact that the MPA approach does not consider the effects of period lengthening in the higher modes, or alternatively phrased, MPA does not account for the fact that yielding in the first mode has an effect on the response of higher modes. This phenomenon is discussed in detail in Sullivan et al. (2008).

As it is clear that higher modes have an appreciable effect on inter-storey drift ratios, the NSAEC8 assessments were repeated with inclusion of higher-mode effects in accordance with Kreslin and Fajfar (2012). The correction factors resulting from Kreslin and Fajfar (KF factors) are shown in Fig. 9(a). They are on average larger for the $T_{D}=4 \mathrm{~s}$ spectrum, which is inconsistent with the observed effects of spectral shape discussed previously. The correction factors appear reasonable at low intensities, but become too large at $a_{\mathrm{g}}=0.3 \mathrm{~g}$ and $0.4 \mathrm{~g}$. This overestimation occurs primarily because the approach does not account for the effect that ductility has on the displaced shape. Well into the inelastic range a large portion of the displacements can be attributed to rigid body rotation about the plastic hinge, which has a proportionally much lower drift in the upper stories than first mode elastic deformations. The Kreslin and Fajfar (2012) method assumes that relationship between roof displacements and drifts is that of an elastically responding structure. 


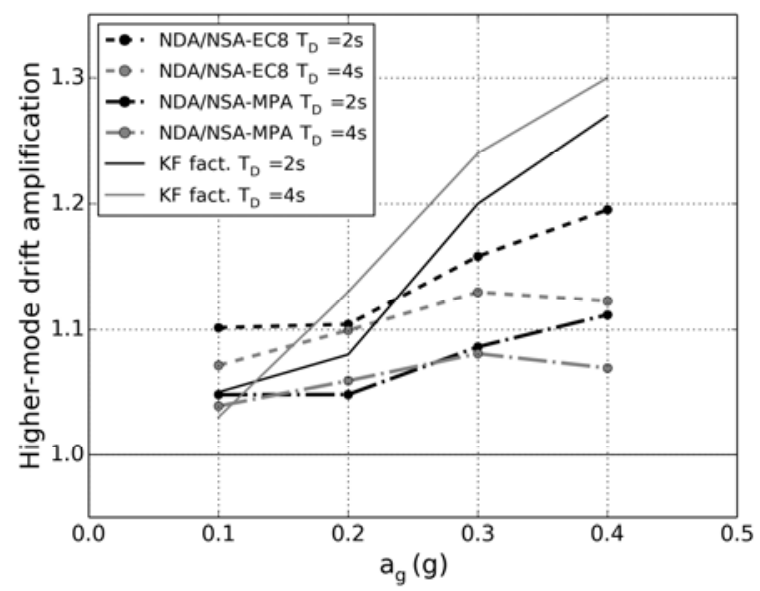

(a)

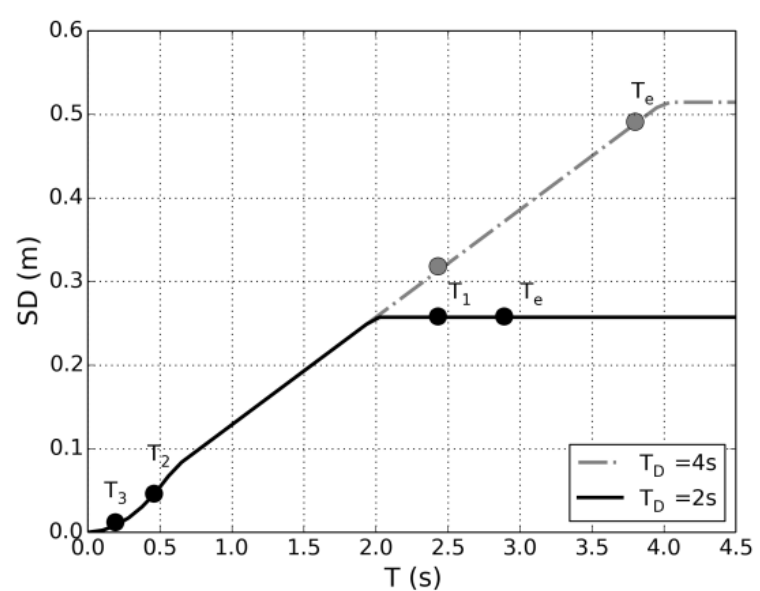

(b)

Fig. 9 (a) Ad hoc higher-mode drift amplification factors ( $\operatorname{IDR}_{\mathrm{NDA}} / \mathrm{IDR}_{\mathrm{NSA}}$ ) versus seismic intensity and correction factors from Kreslin and Fajfar (2012) (KF factors). (b) The two displacement spectra with spectral displacements corresponding to the first three modes identified

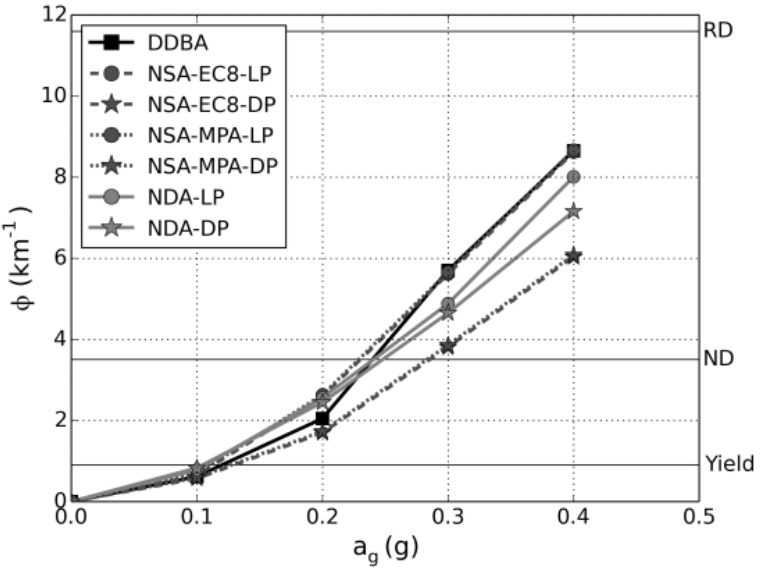

(a)

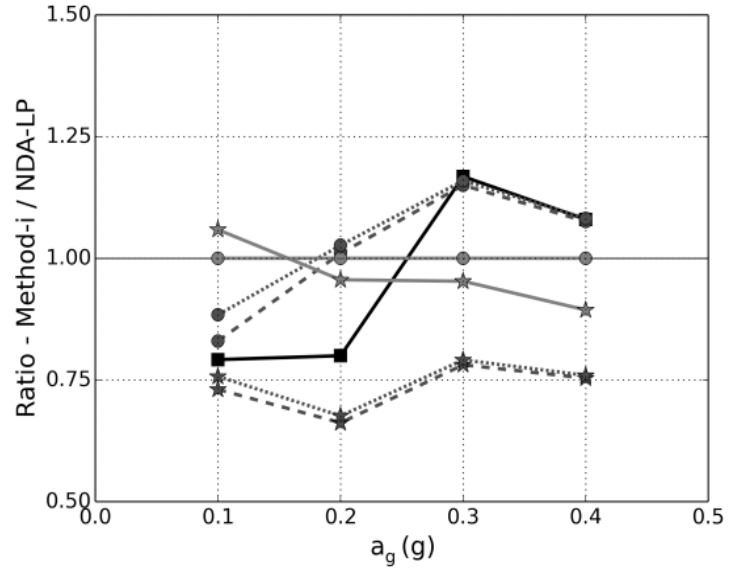

(b)

Fig. 10 Peak wall curvatures versus seismic intensity for $T_{D}=4 \mathrm{~s}$ spectrum. (a) Absolute values, and (b) ratios to benchmark method

As stated previously, curvatures give a good indication of damage as they can be related to material strains. Fig. 10 shows the curvatures at the base of the wall for the $T_{D}=4 \mathrm{~s}$ spectrum. The different procedures and modelling approaches give fairly comparable results; however, there is more scatter than was observed previously for roof displacements and drift. The NSA approaches with DP models give significantly lower curvatures, particularly at low intensities. In terms of performance levels the curvature demands are such that the No Damage limit is reached at around $a_{g}=0.25 \mathrm{~g}$ and the Repairable Damage limit is not reached. This indicates that damage related to material strains in the plastic hinge region is likely to be less severe than drift related damage for the case study building. 


\section{Results for the unequal length walls building}

In the previous section the simple cantilever wall building used four identical walls to resist lateral loads in the EW-direction. Because all four walls were identical it was possible to simplify the assessment down to that of just a single cantilever wall and its tributary mass. In this section the case of unequal length walls is considered. As explained earlier, in this second configuration walls $W 1$ and $W 3$ (refer Fig. 1) are $6 \mathrm{~m}$ long and walls $W 2$ and $W 4$ are $3 \mathrm{~m}$ long. This increases the complexity of the assessment from the previous case as now the different walls must be assessed simultaneously. Furthermore, the manner in which the unequal length walls interact with one another generates additional complexity. As shown in Eq. (14) from Priestley and Kowalsky (1998) the yield curvature of an RC wall is inversely proportional to its length

$$
\phi_{y}=K \frac{\varepsilon_{y}}{L_{W}}
$$

where $K$ is a factor that varies depending on the shape of the wall.

This means that as the building undergoes earthquake excitation the long wall is expected to yield significantly earlier than the short wall. Once the long wall yields, additional displacements are primarily due to rigid body rotation around the base of the wall while the short wall continues to deform elastically. As the two walls must have the same displaced shape (rigid diaphragm assumption) this generates compatibility forces in the floor slabs. These compatibility forces primarily manifest themselves as large variations to the expected shear profiles in the walls, as discussed in Beyer et al. (2014). However, shear forces are not the focus of this work. As shown in Figs. 11 and 12 the effect of using unequal length walls does not appear to significantly affect the ability of the assessment methods to predict roof displacements and drifts. It is logical that unequal wall lengths have little influence on the prediction of roof displacements and drifts, given that the global behaviour is dominated by the long wall, which is significantly stiffer and stronger. Note that for this configuration of the case study building, assessments for $T_{D}=2 \mathrm{~s}$ and with the MPA procedure have not been included as they did not provide any significant results beyond what has already been shown.

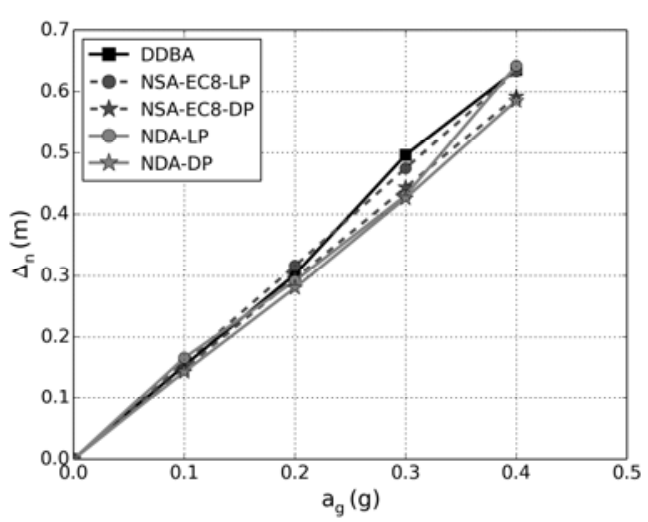

(a)

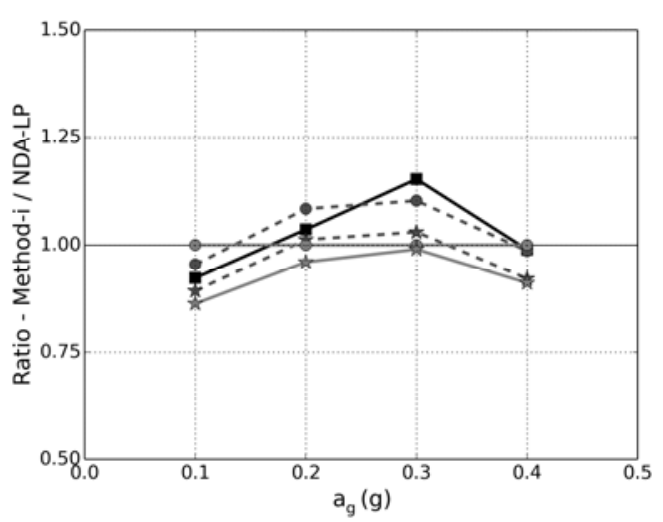

(b)

Fig. 11 Peak roof displacements versus seismic intensity for $T_{D}=4 \mathrm{~s}$ spectrum. (a) Absolute values, and (b) ratios to the NDA-LP benchmark method 
Figs. 13(a) and 13(b) show the curvature demands at the base of the walls. The discrepancies between the different methods are similar to those observed when considering the simple cantilever building. At an intensity of $a_{g}=0.2 \mathrm{~g}$ DDBA significantly underestimates the curvature in the short wall. This is around the point at which both walls are expected to yield; however, this is not captured by DDBA in this example and it cannot be captured easily as there is no numerical model of the structure. This is likely to be of little relevance for seismic assessment though as the curvature demands in the short wall are very low at this intensity. Furthermore, it should be noted that curvature demands are very low in the short wall in general, with the No Damage performance level being exceeded only at the $a_{g}=0.4 \mathrm{~g}$ intensity. A significant difference is observed between the curvature estimates in the long wall obtained using the different modelling approaches with NDA (Fig. 13a). This was not observed with the single cantilever wall, which indicates it is likely due to the compatibility forces affecting local deformations and the ability of the distributed plasticity model to capture any potential yielding outside of the plastic hinge region (which cannot be accounted for in the lumped plasticity model).

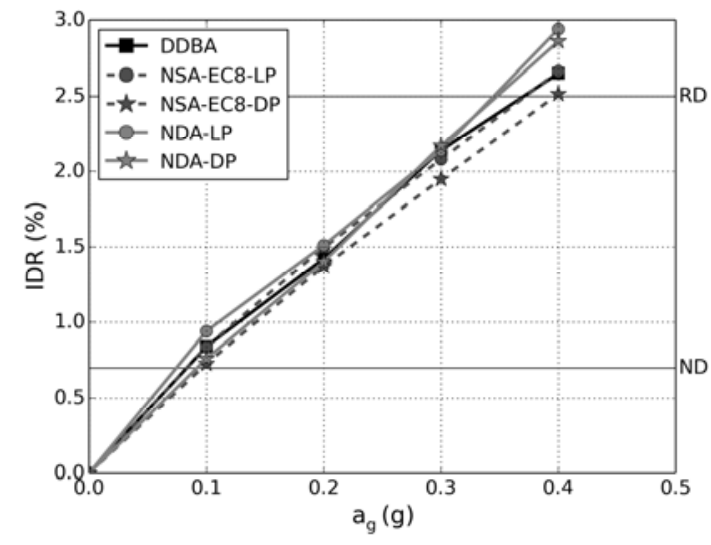

(a)

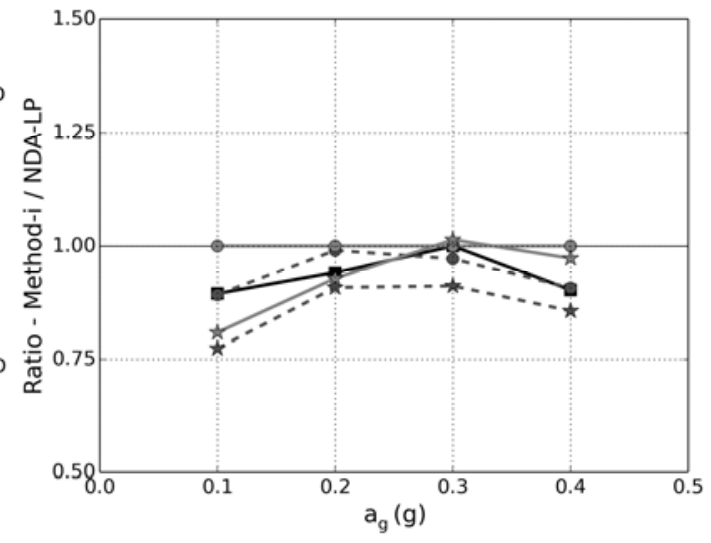

(b)

Fig. 12 Peak drift versus seismic intensity for $T_{D}=4 \mathrm{~s}$ spectrum. (a) Absolute values, and (b) ratios to the NDA-LP benchmark method

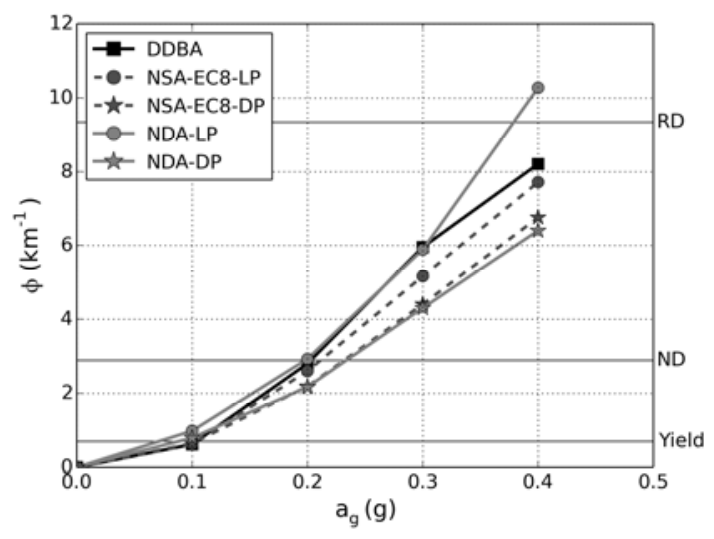

(a)

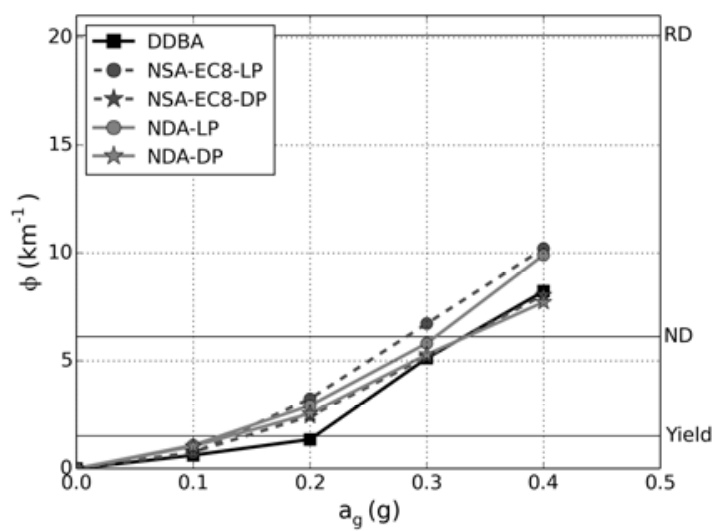

(b)

Fig. 13 Peak curvatures versus seismic intensity for $T_{D}=4 \mathrm{~s}$ spectrum in the (a) long wall, and (b) short wall 


\section{Results for the torsional building}

Assessment of the torsional building is significantly more complex than for the previous buildings as now the $3 \mathrm{D}$ response of the structure must be considered. Therefore, to reduce the overall level of complexity, P- $\Delta$ effects were neglected in assessment and only lumped plasticity modelling was considered. Furthermore, no newly significant observations were made between comparison of $T_{D}=2 \mathrm{~s}$ and $T_{D}=4 \mathrm{~s}$ results and, therefore, results are only provided for the $T_{D}=4 \mathrm{~s}$ spectrum. Fig. 14 shows the maximum roof displacements. As the building is modelled in 3D, there can be multiple measures of roof displacement. In this case the maximum lateral displacements in the EW-direction are given at the stiff (Northern) edge, the flexible (Southern) edge and centre-of-mass (refer to Fig. 1). Also the rotation about the vertical axis is considered.

The most significant observation is that the roof rotation about the vertical axis predicted by the NSA-EC8 approach is significantly less than those predicted by NSA-MPA and NDA methods. The low values for the NSA-EC8 approach are due to two factors. Firstly, there is no applied

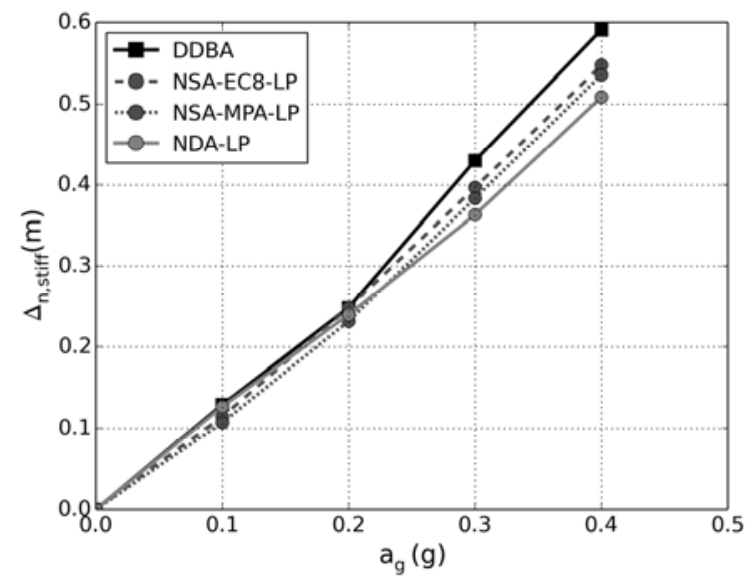

(a)

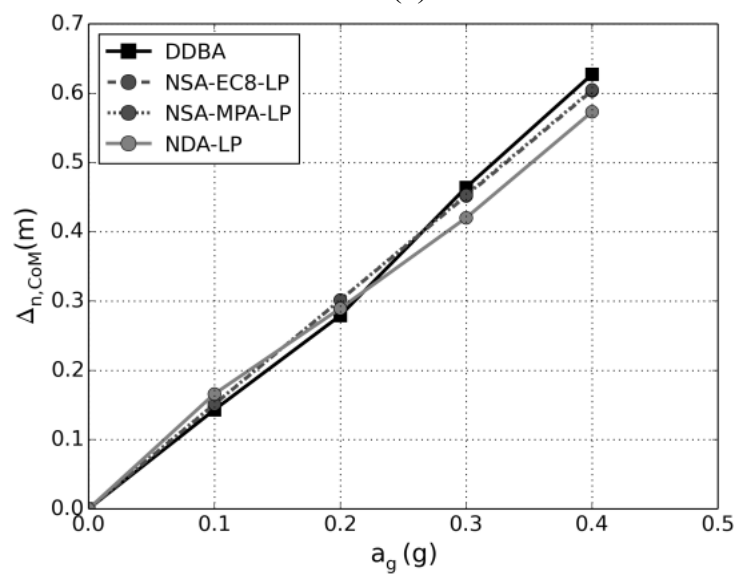

(c)

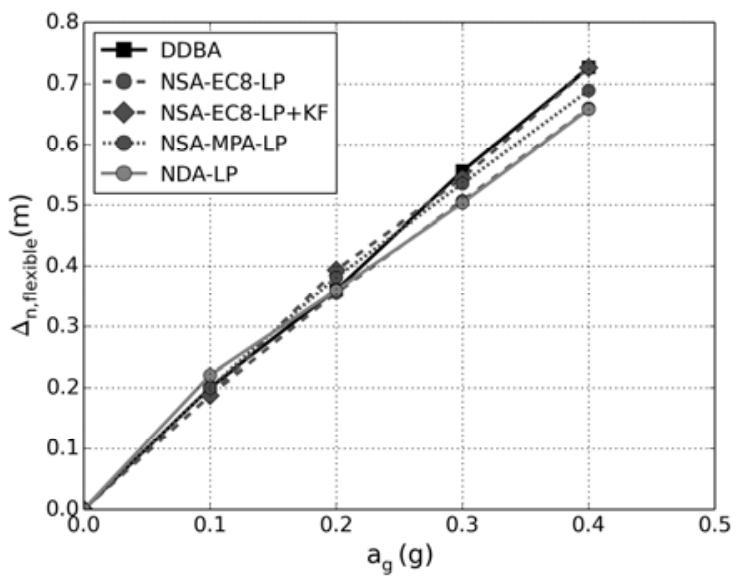

(b)

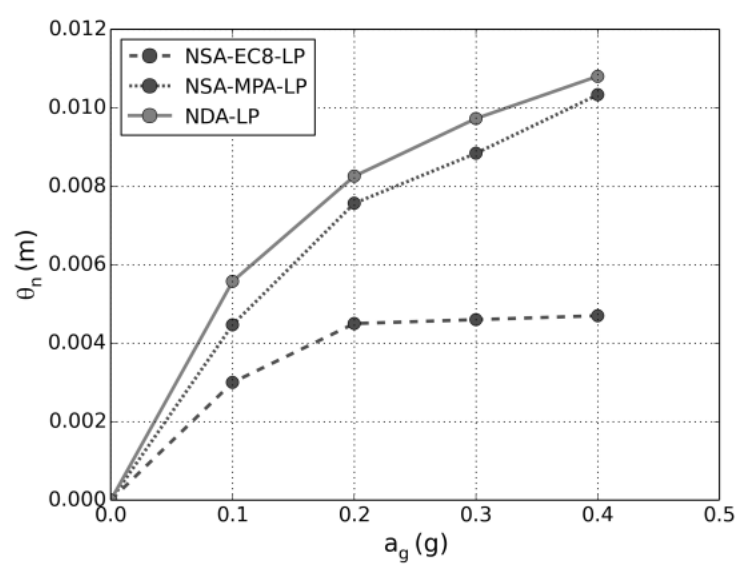

(d)

Fig. 14 Roof displacements versus intensity for $T_{D}=4 \mathrm{~s}$ spectrum. (a) Stiff edge, (b) flexible edge, (c) centreof-mass, and (d) rotation 


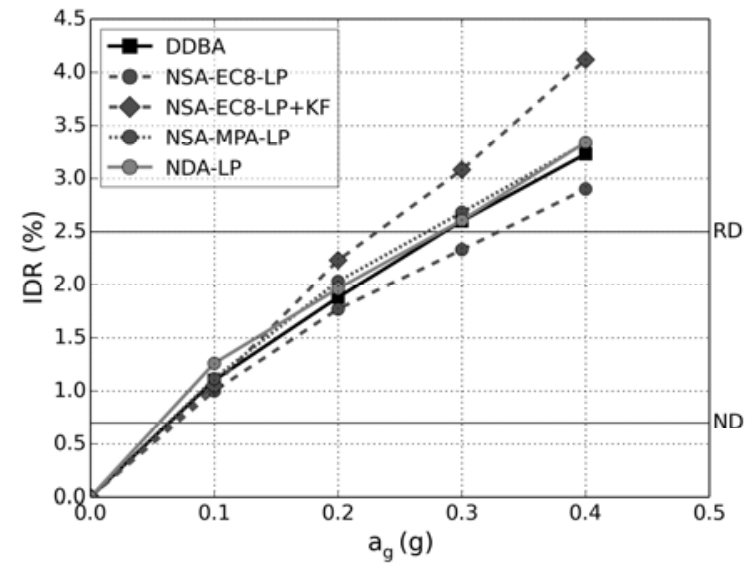

(a)

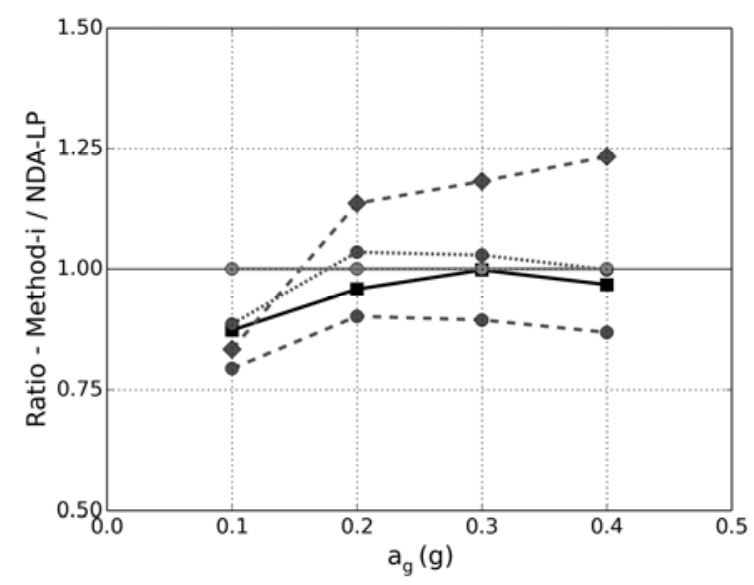

(b)

Fig. 15 Peak drifts at the flexible edge versus intensity for $T_{D}=4 \mathrm{~s}$ spectrum. (a) Absolute values, and (b) ratios to the NDA-LP benchmark method

torque in the loading vector, which results in a roof rotation approximately $30 \%$ less than that obtained for the first mode of the NSA-MPA approach. Secondly, higher modes of response, including torsional modes, are not considered. Note that DDBA calculates a nominal roof rotation but not a true maximum roof rotation and therefore it has not been included in Fig. 14(d). The low rotation for the NSA-EC8 procedure results in larger displacements at the stiff edge and smaller displacements at the flexible edge when compared to the NSA-MPA approach. In general, the edge roof displacements predicted by the NSA procedures are in good agreement with the NDA results. DDBA provides a very good match to the NDA results at low intensities, but at high intensities it tends to overestimate displacements, particularly at the stiff edge. When considering the DDBA results it must be kept in mind that no 3D modelling was required. The NSA-EC8 results were also modified to account for higher-mode effects in plan using the approach of Kreslin and Fajfar (2012). No correction factor was needed for the stiff edge and at the flexible edge correction factors up to 1.11 were obtained. The flexible edge displacements for the Kreslin and Fajfar approach are shown in Fig. 14(b). It is difficult to judge how effective they are as the flexible edge displacements were already overestimated by the NSA-EC8 procedure.

Fig. 15 shows the maximum drifts at the flexible (critical) edge for the different methods. There is good agreement between the different methods except for the NSA-EC8 approach. Without consideration of higher modes it tends to underestimate drift. With consideration of higher modes, drifts are significantly overestimated, particularly at high intensities. This is again due to the elastic displaced shape assumption of the Kreslin and Fajfar (2012) approach that was already discussed in reference to the simple cantilever wall building.

\section{Recommendations}

The previous sections have identified a number of advantages and disadvantages of the seismic assessment procedures currently available, both in terms of accuracy and reliability of results and of the effort and expertise required to undertake the procedure. Based on the observations made, 
Table 5 Recommended assessment procedures and modelling approaches for different scenarios (KEY: $\checkmark \checkmark$-good; $\checkmark$-adequate, $\boldsymbol{x}$-not recommended, N/A-not applicable)

\begin{tabular}{|c|c|c|c|c|c|c|}
\hline & \multicolumn{4}{|c|}{ Assessment procedure } & \multicolumn{2}{|c|}{ Modelling strategy } \\
\hline & DDBA & NSA-EC8 & NSA-MPA & NDA & LP & DP \\
\hline IDR likely to be critical EDP & $\checkmark$ & $\checkmark$ & $\checkmark$ & $\checkmark$ & $\checkmark$ & $\checkmark$ \\
\hline $\begin{array}{l}\text { Higher modes expected to affect } \\
\text { IDR }\end{array}$ & $x^{1}$ & $x^{1}$ & $x^{2}$ & $\checkmark \checkmark$ & $\checkmark$ & $\checkmark$ \\
\hline $\begin{array}{c}\text { Curvature likely to be critical } \\
\text { EDP }\end{array}$ & $\checkmark$ & $\checkmark$ & $\checkmark$ & $\checkmark$ & $\checkmark$ & $\checkmark$ \\
\hline Torsional response expected & $\checkmark$ & $\checkmark^{3}$ & $\checkmark$ & $\checkmark \checkmark$ & $\checkmark$ & $\checkmark$ \\
\hline $\begin{array}{l}\text { Effective period expected to } \\
\text { significantly exceed } T_{D}\end{array}$ & $x^{4}$ & $x^{4}$ & $x^{4}$ & $\checkmark$ & $\checkmark$ & $\checkmark$ \\
\hline $\begin{array}{l}\text { Advanced modelling software } \\
\text { not available }\end{array}$ & $\checkmark \checkmark^{5}$ & $x$ & $x$ & $x$ & N/A & N/A \\
\hline $\begin{array}{c}\text { High level of expertise not } \\
\text { available }\end{array}$ & $\checkmark$ & $\checkmark$ & $\checkmark$ & $x^{6}$ & $\checkmark$ & $\checkmark$ \\
\hline $\begin{array}{l}\text { Tall building with large number } \\
\text { of walls }\end{array}$ & $\checkmark$ & $\checkmark$ & $\checkmark$ & $\checkmark$ & $\checkmark$ & $x^{7}$ \\
\hline
\end{tabular}

this section provides recommendations as to which method(s) would be most suited to particular situations. This is provided in a summary format in Table 5, with the following explanations for various decisions (each referring to a number given in the table):

1) In this application higher-mode effects were not considered for the DDBA or NSA-EC8 approaches; however, it was shown that even for an eight storey building, higher-mode drift amplification can be significant. Although there is the Kreslin and Fajfar (2012) approach to include higher-mode effects in the N2 method, it appears that further development of this approach is required for RC wall buildings. In particular, accounting for the effect that yielding in the first mode has on the displaced shape (i.e., the relationship between peak drift and roof displacement).

2) Although the MPA procedure includes higher modes, it does not account for period lengthening and can therefore be slightly unconservative in estimating drifts in RC wall buildings.

3) The NSA-EC8 procedure was of limited accuracy in estimating drift demands in the torsional building. It is foreseeable that more severe configurations could worsen the results.

4) The existing relationships for relating elastic to inelastic displacement demand do not appear to be well suited to the plateau of the displacement spectrum. It is expected that these methods could be effective for periods greater than $T_{D}$ once modified inelastic displacement relationships become available.

5) DDBA in fact requires no finite element software and can be undertaken with just hand calculations (although spreadsheet capabilities are a significant benefit). This makes the approach particularly powerful in situations where resources are limited.

6) It is considered that the expertise required to run nonlinear dynamic analyses is significantly more than for the other methods. In particular for the reasons such as ground-motion selection and damping modelling.

7) Given the computational expense of distributed plasticity beam elements this is not an attractive option. Particularly for nonlinear dynamic analyses with a large number of ground motions. 


\section{Conclusions}

A number of different seismic assessment procedures and modelling approaches have been applied to a case study RC wall building configured in three different ways. The assessment procedures include Direct Displacement-Based Assessment, nonlinear static analysis and nonlinear dynamic analysis and the case study configurations examined the effects of unequal length walls and torsional effects. Both lumped and distributed plasticity modelling approaches were used. Various merits and drawbacks of each approach have been identified and recommendations made as to which scenarios certain procedures are more suited to.

In particular it has been shown that both Direct Displacement-Based Assessment and nonlinear static analysis, which can be considered as simplified approaches, can generally produce results comparable to those obtained from nonlinear dynamic analyses. There are however some areas of the simplified approaches that need improvement. Firstly, the relationships between elastic spectral displacement and inelastic response of equivalent SDOF systems need development for the region of the spectrum near and beyond the corner period $T_{D}$. This was shown through the assessment of the case study building using two displacement spectra with different corner periods. Secondly, it has been shown that the existing approaches to account for higher-mode drift amplification need to be enhanced to account for the effects of period lengthening and in the case of the Kreslin and Fajfar (2012) approach, to account for the influence that yielding has on the displaced shape of the structure and its subsequent influence on higher-mode correction factors. The simplified procedures offer significant advantages over nonlinear dynamic analyses in terms of their simplicity. Specifically, they do not require consideration of a damping model, hysteretic model or ground-motion selection. This is particularly true for Direct Displacement-Based Assessment, which does not require numerical modelling at all. Furthermore, the simplified methods can offer considerable savings in computational time.

Comparisons were also made between lumped and distributed plasticity modelling approaches. At high intensities the differences in estimations of EDPs between the two models in a nonlinear dynamic analysis framework were minor, the exception being curvature estimates in the unequal length walls building. At low intensities the differences in stiffness (prior to yield) between the two modelling approaches had a more significant effect and gave lower estimates of drifts and displacements for the distributed plasticity model. Similarly, the differences in stiffness had an effect on the bilinearisation used for the NSA procedures, which in turn gave differences in EDP estimates.

This work was limited to the consideration of deformations only. Future work should compare the same approaches in their ability to estimate shear forces and bending moments.

\section{Acknowledgments}

The research described in this paper received financial support from the Italian department of Civil Protection (DPC) via the EUCENTRE-DPC 2014 project C2.2a.

\section{References}

Almeida, J.P., Tarquini, D. and Beyer, K. (2014), "Modelling approaches for inelastic behaviour of RC 
walls: multi-level assessment and dependability of results", Archives of Computational Methods in Engineering, published online.

Antoniou, S. and Pinho, R. (2004), "Development and verification of a displacement-based adaptive pushover procedure", J. Earthq. Eng., 8(5), 643-661.

Baker, J.W. (2011), "Conditional mean spectrum: tool for ground-motion selection”, J. Struct. Eng., 137(3), 322-331.

Beyer, K., Dazio, A. and Priestley, M.J.N. (2008), Seismic design of torsionally eccentric buildings with Ushaped RC walls, Research Report No. ROSE-2008/03, IUSS Press, Pavia, Italy.

Beyer, K. and Bommer, J.J. (2007), "Selection and scaling of real accelerograms for bi-directional loading: a review of current practice and code provisions", J. Earthq. Eng., 11(S1), 13-45.

Beyer, K., Simonini, S., Constantin, R. and Rutenberg, A. (2014), "Seismic shear distribution among interconnected cantilever walls of different lengths", Earthq. Eng. Struct. Dyn., 43(10), 1423-1441.

Carr, A.J. (2007), Ruaumoko Manual - Volume 1: Theory, Department of Civil Engineering, University of Canterbury.

Carr, A.J. (2008), Ruaumoko Manual - Volume 5: Appendices, Department of Civil Engineering, University of Canterbury.

Carr, A.J. (2012) Ruaumoko Manual - Volume 3: User manual for the 3-dimensional version Ruaumoko3D, Department of Civil Engineering, University of Canterbury, New Zealand.

Castillo, R. (2004), Seismic Design of Asymmetric Ductile Systems, PhD Thesis, University of Canterbury, Christchurch, New Zealand.

Chopra, A.K. (2007), Dynamics of Structures - Theory and Application to Earthquake Engineering, $3^{\text {rd }}$ edition, Prentice Hall, New Jersey.

Chopra, A.K. and Goel, R.K. (2001), "A modal pushover analysis procedure for estimating seismic demands: Evaluation for SAC building", Proceedings of SEAOC Convention, San Diego.

Chopra, A.K. and Goel, R.K. (2002), "A modal pushover analysis procedure for estimating seismic demands for buildings", Earthq. Eng. Struct. Dyn., 31(3), 561-582.

Chopra, A.K. and Goel, R.K. (2004), "A modal pushover analysis to estimate seismic demands for unsymmetric-plan buildings", Earthq. Eng. Struct. Dyn., 33(8), 903-927.

Clough, R.W. and Penzien, J. (1993), Dynamics of Structures, McGraw-Hill, New York.

Comité Européen de Normalisation (2004), "Eurocode 8, Design of Structures for Earthquake Resistance Part 1: General Rules, Seismic Actions and Rules for Buildings", EN 1998-1, CEN, Brussels, Belgium.

Comité Européen de Normalisation (2005), "Eurocode 8, Design of structures for earthquake resistance Part 3: Assessment and retrofitting of buildings", EN 1998-3, CEN, Brussels, Belgium.

Correia, A.A., Almeida, J.P. and Pinho, R. (2013), "Seismic Energy Dissipation in Inelastic Frames: Understanding State-of-the-Practice Damping Models", Struct. Eng. Int., 23(2), 148-158.

De Luca, F., Vamvatsikos, D. and Iervolino, I. (2011), "Near-optimal bilinear fit of capacity curves for equivalent SDOF analysis", Proceedings - $3^{\text {rd }}$ International Conference on Computational Methods in Structural Dynamics and Earthquake Engineering, Corfu, Greece.

Fajfar, P. (1999), "Capacity spectrum method based on inelastic demand spectra", Earthq. Eng. Struct. Dyn., 28(9), 979-993.

Fajfar, P. (2000), "A nonlinear analysis method for performance-based seismic design", Earthq. Spectra, 16(3), 573-592.

Filippou, F.C., Popov, E.P. and Bertero, V.V. (1983), "Effects of bond deterioration on hysteretic behaviour of reinforced concrete joints", Report EERC 83-19, Earthquake Engineering Research Center, University of California, Berkeley.

Fox, M.J. Sullivan, T.J. and Beyer, K. (2014), “Comparison of force-based and displacement-based design approaches for RC coupled walls in New Zealand”, Bull. NZ. Soc. Earthq. Eng., 47(3), 190-205.

FEMA-273 (1997), "NEHRP guidelines for the seismic rehabilitation of buildings", Federal Emergency Management Agency, Washington DC.

Gulkan, P. and Sozen, M. (1974), "Inelastic response of reinforced concrete structures to earthquake motions", ACI J., 71(12), 604-610. 
Gupta, B. and Kunnath, S.K. (2000), "Adaptive spectra-based pushover procedure for seismic evaluation of structures", Earthq. Spectra, 6(2), 367-392.

Iervolino, I., Maddaloni, G. and Cosenza, E. (2008), "Eurocode 8 compliant real record sets for seismic analysis of structures", J. Earthq. Eng., 12(1), 54-90.

Kreslin, M. and Fajfar, P. (2012), "The extended N2 method considering higher mode effects in both plan and elevation", Bull. Earthq. Eng., 10(2), 695-715.

Mander, J.B., Priestley, M.J.N. and Park, R. (1988), "Theoretical stress-strain model for confined concrete", J. Struct. Eng., 114(8), 1804-1826.

Martinez-Rueda, J.E. and Elnashai, A.S. (1997), "Confined concrete model under cyclic load", Mater. Struct., 30(197), 139-147.

Menegotto, M. and Pinto, P.E. (1973), "Method of analysis for cyclically loaded R.C. plane frames including changes in geometry and non-elastic behaviour of elements under combined normal force and bending", Symposium on the Resistance and Ultimate Deformability of Structures Acted on by Well Defined Repeated Loads, International Association for Bridge and Structural Engineering, Zurich, Switzerland.

Paulay, T. (2001), "Some design principles relevant to torsional phenomena in ductile buildings", J. Earthq. Eng., 5(3), 273-308.

Pennucci, D., Sullivan, T.J. and Calvi, G.M. (2015), "Inelastic higher-mode response in reinforced concrete wall structures", Earthq. Spectra, 31(3), 1493-1514.

Priestley, M.J.N. and Kowalsky, M.J. (1998), "Aspects of drift and ductility capacity of rectangular cantilever structural walls", Bull. NZ. Soc. Earthq. Eng., 31(4), 246-259.

Priestley, M.J.N, Calvi, G.M. and Kowalsky, M.J. (2007), Displacement-Based Seismic Design of Structures, IUSS Press, Pavia, Italy.

Priestley, M.J.N. and Grant, D.N. (2005), "Viscous damping in seismic design and analysis", J. Earthq. Eng., 9(sup2), 229-255.

Scott, M.H. and Fenves, G.L. (2006), "Plastic hinge integration methods for force-based beam-column elements", J. Struct. Eng, 132(2), 244-252.

Seismosoft (2013), SeismoStruct v6.5 - A computer program for static and dynamic nonlinear analysis of framed structures, http://www.seismosoft.com.

Smerzini, C., Galasso, C., Iervolino, I. and Paolucci, R. (2014), "Ground motion record selection based on broadband spectral compatibility", Earthq. Spectra, 30(4), 1427-1448.

Sullivan, T.J., Priestley, M.J.N. and Calvi, G.M. (2008), "Estimating the higher-mode response of ductile structures", J. Earthq. Eng., 12(3), 456-472.

Sullivan, T.J., Calvi, G.M. and Priestley, M.J.N. (2012), A Model Code for the Displacement-Based Seismic Design of Structures DBD12, IUSS Press, Pavia, Italy.

Sullivan. T.J., Welch, D.P. and Calvi, G.M. (2014), "Simplified seismic performance assessment and implications for seismic design", Earthq. Eng. Eng. Vib., 13(Supp.1), 95-122.

Veletsos, A.S. and Newmark, N.M. (1960), "Effect of inelastic behaviour on the response of simple systems to earthquake motions", Proceedings - Second World Conference on Earthquake Engineering, Vol. II, Tokyo, Japan.

Welch, D.P., Sullivan, T.J. and Calvi, G.M. (2014), "Developing direct displacement-based procedures for simplified loss assessment in performance-based earthquake engineering", J. Earthq. Eng., 18(2), 290322.

Yazgan, U. and Dazio, A. (2010), "Critical aspects of finite element modeling of RC structures for seismic performance assessment", Proceedings of the $9^{\text {th }}$ U.S. National and $10^{\text {th }}$ Canadian Conference on Earthquake Engineering, Toronto, Canada. 